\title{
Metonymy as a prototypical category
}

YVES PEIRSMAN and DIRK GEERAERTS*

Abstract

A definition of metonymy that has gained some popularity in Cognitive Linguistics contrasts metonymical semantic shifts within a domain or domain matrix with metaphorical shifts that cross domain boundaries. In the past few years, however, this definition of metonymy has become subject to more and more criticism, in the sense that it relies too much on the vague notions of domains or domain matrices to be fully reliable. In this article, we address this problem by focusing on a nonunitary, prototypical definition of contiguity (the concept that used to be seen as the defining feature of metonymy before Cognitive Linguistics introduced domains and domain matrices). On the basis of the traditional pre-structuralist literature on metonymy, we identify a large number of typical metonymical patterns, and show that they can be classified in terms of the type of contiguity they are motivated by. We argue that metonymies, starting from spatial partwhole contiguity as the core of the category, can be plotted against three dimensions: strength of contact (going from part-whole containment over physical contact to adjacency without contact), boundedness (involving an extension of the part-whole relationship towards unbounded wholes and parts), and domain (with shifts from the spatial to the temporal, the spatiotemporal and the categorial domain).

Keywords: metonymy; prototypicality.

\section{Introduction}

The discussion of metonymy in the context of Cognitive Linguistics has so far concentrated on a definition of metonymy as a shift of meaning within one domain or domain matrix (Kövecses 2002: 145). It is gradually becoming clear, however, that this definition relies too much on the 
vague notion of "domain (matrix)" to be fully operational; see Taylor (2002) or Ruiz de Mendoza and Otal Campo (2002) among a number of critical voices. Various linguists (among them Croft and Cruse 2004; Feyaerts 1999; Riemer 2001) now suggest that it is less than straightforward to use identity versus difference between the semantic domains involved as a basis for the differentiation of metaphor and metonymy.

At the same time, however, a simple return to the older definition of metonymy in terms of contiguity (see Ullmann 1967) is precluded. After all, this unitary definition is as problem-ridden as a unitary definition in terms of domains or domain matrices. Rather, it would seem that a non-unitary definition of metonymy is called for. And the obvious way of constructing such a definition in Cognitive Linguistics is to use a prototype-theoretical model of categorization.

This prototypically structured category needs to account for the wide variety of metonymical patterns that can be found in the linguistic literature. Section 2 therefore presents the empirical basis of the paper, a list of metonymical patterns that is nowadays widely accepted by linguists. This list was compiled to a large extent on the basis of the pre-structuralist literature on diachronic semantics (specifically from the works of Esnault 1925; Nyrop 1913; Paul 1880; Waag 1901). While the current interest in metonymy (since Nunberg's 1978 seminal work) has a mainly theoretical orientation, the pre-structuralist tradition is still, descriptively speaking, the richest source on varieties of metonymy. The analytical part of the paper, Sections 3 to 6 , argues that these metonymical types can all be related to the prototypical core of spatial part-whole contiguity. The relations between this core case and the derived types (and between the extended types among each other) can be plotted against three dimensions: strength of contact (going from part-whole containment over physical contact to adjacency without contact), boundedness (involving an extension of the part-whole relationship towards unbounded wholes and parts), and domain (with shifts from the spatial to the temporal, the spatio-temporal and the categorial domain). As may be expected in a prototypically structured category, these dimensions interact in various ways.

\section{The cognitive linguistic view of metonymy}

The most widespread definition of metonymy in Cognitive Linguistics is the following one:

Metonymy is a cognitive process in which one conceptual entity, the vehicle, provides mental access to another conceptual entity, the target, within the same domain, or idealized cognitive model (ICM). (Kövecses 2002: 145). 
The appeal of this definition lies not only in its unitary character, but also in the clear way in which it seems to distinguish between metonymy and metaphor: metonymy is a shift within one domain; metaphor is a shift across domains.

In spite of its popularity (e.g. Barcelona 2002; Kövecses 2002; Kövecses and Radden 1998; Panther and Thornburg 1999), however, this single-domain approach has also been the object of much criticism. First, the notion of "domain" is not well-defined: "What constitutes one domain has to date not been satisfactorily elucidated in the literature and remains a topic for future research" (Panther and Thornburg, in press). Second, as Croft (2002) notes, metonymies regularly seem to cross domain boundaries. In Proust is tough to read, for instance, the source belongs to the domain of human beings, but the target to that of creative activity. There are thus indications that the definition above needs to be revised.

Croft (2002) proposes to replace "domain" by "domain matrix". $\mathrm{He}$ shows that "a concept is profiled against an often very complex domain structure or matrix, even if there is only one abstract domain as the base" (Croft 2002: 177). Croft (2002: 179) claims that metonymy involves "domain highlighting (see e.g. Cruse 1986: 53), since the metonymy makes primary a domain that is secondary in the literal meaning". Hence, the definition of metonymy should be rephrased as "a metonymic mapping [which] occurs within a single domain matrix, not across domains (or domain matrices)" (Croft 2002: 177).

Still, this proposal does not solve all problems. Although it successfully addresses the topic of metonymies that cut across domain boundaries, it further seems to face the same problem as a definition in terms of domains as such. Feyaerts (1999: 318) notes that semantic structures, and thus domain matrices as well as domains, are "experientially based and consequently to a large extent individually determined". Moreover, Taylor (2002: 196-197) claims that "it would be an error to suppose that domains constitute strictly separated configurations of knowledge; typically, domains overlap and interact in numerous and complex ways". These observations suggest that domain matrix descriptions of a metonymical meaning shift often apply only a posteriori, that is to say, it is often only after the metonymical shift has occurred that we can see that a certain feature is a relevant part of the domain matrix.

Consider the Italian word moneta, "coin", which is derived from the Roman name Juno Moneta, the goddess whose temple was used as a mint in Rome. This shift of meaning may be accounted for after the fact in terms of conceptual relationships between two entities within a domain matrix (the goddess and the temple, the temple and the coins). However, 
if we were to describe the domain matrices while being unaware of the metonymic shift, these relationships would not easily be recognized as relevant. The notion of domain matrix, in other words, appears to be a very general one that does not restrict the set of possible metonymies very much. A restriction on possible metonymical meaning shifts, by contrast, would seem to require a more detailed description of the relationships that they are motivated by.

Croft's (2002) notion of "domain highlighting" is not without its problems either. Ruiz de Mendoza and Otal Campo (2002) show that this phenomenon occurs in metaphor, too, and Feyaerts (1999: 319) similarly argues that "one cannot exclude metaphoric mappings taking place within the boundaries of a domain matrix". In Goossens's (1995) example "Oh dear," she giggled, "I'd quite forgotten", for instance, giggle can be interpreted metonymically as well as metaphorically. In the metonymical interpretation it means "to say something while giggling"; in the metaphorical one it means "to say something as if giggling". Feyaerts (1999), unlike Goossens (1995), sees no reason whatsoever to conclude that in the metaphorical reading "the domain (HUMAN) SOUND does not belong to the domain matrix of the profiled concept linguistic action" (Feyaerts 1999: 320). Instead, he considers the auditory experience "an essential aspect of every linguistic utterance" (Feyaerts 1999: 320), and thus a part of the same domain matrix. A similar example is the Dutch vingers op het raam, "fingers on the window". This phrase can be explained metaphorically, where the crucial relationship is the similarity between the fingers and their prints on the window, as well as metonymically, where everything fingers can do belongs to the "finger" domain matrix. Yet, in spite of these two different explanations, the entities and domains involved remain the same. The inclusion of two entities within the same matrix and the highlighting of a secondary subdomain are thus not restricted to metonymy.

In the light of the arguments above, Croft and Cruse (2004), Feyaerts $(1999,2000)$ and Riemer (2001) all agree that

... it is unwise to use identity versus difference between the semantic domains involved as a basis for the differentiation of metaphor and metonymy: the determination of the two should not be based on considerations of semantic domain in the absence of independent means of delimiting these, because one's definition of semantic domain would be crucial for the classification of a meaning transfer as one or the other. (Riemer 2001: 383).

There are two possible ways of dealing with this problem. The first would be to try and find better criteria of delineating the conceptual entities 
within which metonymies operate. Barcelona (2002) and Kövecses and Radden (1998), for instance, suggest replacing domains by frames or ICMs, which are easier to define. The second approach shifts its attention from the domain matrices underlying the metonymical mapping to the specific nature of this mapping, which is, for instance, more asymmetric than the one in metaphor. It defines metonymy "in terms of the nature of the conceptual relationship rather than the range of the extension visà-vis the boundaries of a domain matrix" (Feyaerts 1999: 317).

In this paper, we take the second approach, since we identify metonymy in terms of contiguity (as opposed to similarity, which yields metaphor). In a long-standing linguistic tradition, this notion of contiguity has been specified in terms of referential contiguity (e.g. Norrick 1981), in terms of several kinds of linguistic contiguity (Eco 1973; Jakobson 2002; Ullmann 1967) and finally in terms of conceptual contiguity (Dirven 2002; Feyaerts 1999; Schmid 1993). The first conception sees contiguity as a number of objective relationships (such as part-whole and adjacency) that exist in the referential world. The second defines it as a linguistic phenomenon, either as the relationship between two elements that are syntagmatically combined (Jakobson 2002) or as the relationship between the senses or "semes" of a word (Eco 1973). Cognitive Linguistics, finally, starts from a modified version of the referential approach, stressing that the relations that lie at the basis of metonymic shifts of meaning are not just objectively given, but rely on a process of construal (Dirven 2002: 88). It is this last conceptual definition of contiguity that will form the backbone of our analysis of metonymy, and which will allow us to extend the category to include non-referential cases.

Importantly, this new stress on contiguity rather than on domains or domain matrices does not require us to use a unitary definition of contiguity. After all, the concept of contiguity is no less vague than that of domain or domain matrix. We will therefore argue (not surprisingly in the context of Cognitive Linguistics) that metonymy is a prototypically structured concept. This prototypicality of metonymy (as well as metaphor) was already suggested by, for instance, Barcelona $(2002,2003)$ and Dirven (2002). Barcelona focused on varying degrees of "metonymicity", as opposed to literal language, while Dirven uncovered a continuum from metonymy to metaphor, in terms of conceptual distance between source and target. By contrast, we want to reveal conceptual relationships within the category of metonymy itself.

Some existing studies of metonymy already offer a number of useful perspectives. Blank's (1999) hierarchical view of contiguity and metonymy in particular will return in our sections 3 to 6 . Our analysis, however, will be more fine-grained than Blank's (1999), in that it systematically 
investigates the relations between metonymical patterns, some of which have already been suggested by Kövecses and Radden (1998). In this way we will be able to show that the same types of contiguity recur in different domains of conceptualization, as in Seto's (1999) classification.

Our general approach, then, is quite similar to Blank's (1999). Blank (1999) combines an abstract classification of types of contiguity with concrete metonymical patterns. He identifies a hierarchy of three abstract levels that lie at the basis of metonymy. On the highest level, Blank (1999) argues, there are two "domains of contiguity". These two domains, copresence and succession, roughly correspond to Bonhomme's (1987) "métonymies situatives" and "métonymies actancielles" and give rise to an open list of "types of contiguity" on the second level. These can "best be compared to the 'image schemas' underlying metaphors (see e.g. Lakoff and Johnson 1980; Johnson 1987), which are highly recurrent and conventionalized, but nevertheless build on an open list" (Blank 1999: 183). It is these various types of contiguity that lead to the concrete metonymies on the lowest level. Blank's (1999) classification is thus useful in that it relates concrete metonymical patterns to higher-level subtypes of contiguity. Still, the specific kinds of contiguity and the relations between the various metonymical patterns are left for the reader to discover. In the present paper, we will address this issue by establishing a prototypical core from which other patterns can be derived and by investigating in what way these patterns are related to each other and to the core.

Some of these detailed relations have already been noted by Kövecses and Radden (1998). They mention, for instance, that there exists a metaphorical link between CATEGORY \& PROPERTY ${ }^{1}$ and POSSESSOR \& POSSESSED: "[T] he relationship between a category and one of its properties may be analyzed as a special, metaphorical case of the relationship between a possessor and his possessions" (Kövecses and Radden 1998: 53). This means that a metonymy such as jerk for "stupidity" (CATEGORY FOR DEFINING PROPERTY) can be seen as metaphorically akin to cases such as This is Harry for "Harry's drink" (POSSESSOR FOR POSSESSED). Unfortunately, Kövecses and Radden (1998) mention such motivating relationships between concrete patterns only sporadically. We will argue, instead, that they form the fundamental tissue that keeps the metonymical category together.

Moreover, the same relationships seem to appear in different "domains of contiguity", in Blank's (1999) terms. Seto's (1999) classification, for instance, nicely shows how the temporal domain of metonymy mirrors the spatial domain. Seto distinguishes between three kinds of spatial metonymies: whole-part, container-contents and adjacency (see Figure 1). Some examples are He picked up the telephone for whole-part, The kettle is 


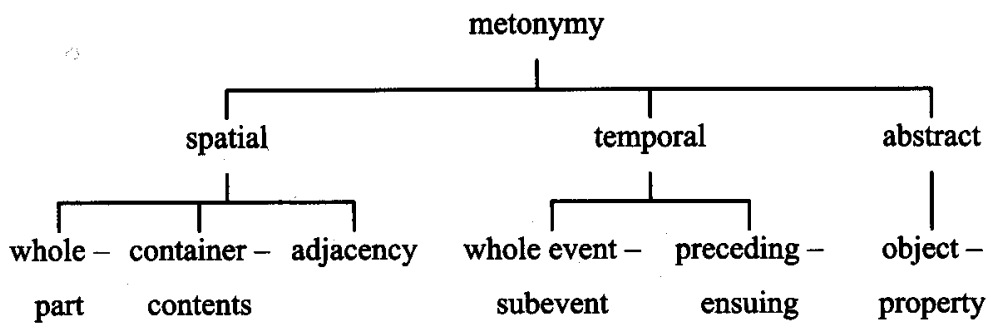

Figure 1. Types of metonymy according to Seto (1999).

boiling for container-contents and He looked at his wrist. "I'd better get back to work" for adjacent relations that "resist a neat classification" (Seto 1999: 104). Two of these classes, viz. "whole-part" and "adjacency", again crop up in the temporal domain. First, "whole-part" is reflected in "whole event-subevent", which involves a complex event and a part of that event. A good example is $\mathrm{He}$ is reading for his first degree, where reading is just a part of the more complex action of studying. "Adjacency", second, is reflected in "preceding-ensuing", which involves two events that closely follow each other. A good example here is I felt fiercely proud of my mother for standing up for her righteous neighbors: the action of standing up is "adjacent" to the action of defending people. This correspondence between the spatial and the temporal domain suggests that they are closely related.

In short, by linking up with suggestions that are already present in the recent work of scholars like Riemer, Barcelona, Dirven, Blank, Feyaerts and Seto, the analysis of metonymy that we will develop in the following sections represents a logical step forward in the Cognitive Linguistic study of metonymy. The identification of various levels of contiguity, the detailed relationships between concrete metonymical patterns, and the correspondence between various domains of contiguity have already been suggested, albeit sometimes reluctantly, by other studies. To these earlier insights, however, we now add an attempt to structure the inventory of metonymical patterns in prototype-theoretical terms.

\section{An inventory of metonymical patterns}

In order to come to a prototypical classification of metonymy, we need to establish an empirical basis of metonymical patterns that linguists generally agree upon. Lists of such patterns can be found particularly in pre-structuralist studies of semantics (cp. Geeraerts 1988 for the importance of pre-structuralist semantics for Cognitive Linguistics). We have 
consulted three major early studies, Prinzipien der Sprachgeschichte by Hermann Paul (1880), Grammaire historique de la langue française by Kristoffer Nyrop (1913) and Bedeutungsentwicklung unseres Wortschatzes by Albert Waag (1901), together with Gaston Esnault's Métaphores occidentales (1925) and Neal R. Norrick's Semiotic Principles in Semantic Theory (1981). If we combine the five lists of metonymical patterns these books present, the following (still unstructured) inventory emerges. ${ }^{2}$

1. SPATial PaRt \& Whole (P) (W) (Ny) (E) (No) ${ }^{3}$

Tony Blair is the Prime Minister of England. ${ }^{4}$

2. TEMPORAL PART \& WHOLE (W)

Dutch and German morgen "morning" for "tomorrow" (Waag 1901: 92)

3. LOCATION \& LOCATED (P) (W) (Ny) (E) (No)

German Das ganze Haus wurde aus dem Schlaf geschreckt (Waag 1901: 96).

4. ANTECEDENT \& CONSEQUENT (P) (W) (Ny) (E)

Greek phobos "flight" for "fear" (Nyrop 1913: 213)

5. SUBEVENT \& COMPLEX EVENT (P) (W) (No)

Mother is cooking potatoes (Kövecses 2002: 153).

6. CHARACTERISTIC \& ENTITY (P) (W) (Ny) (E)

French beauté "beauty" (Nyrop 1913: 224)

7. PRODUCER \& PRODUCT (P) (W) (Ny) (E) (No)

I'm reading Shakespeare (Kövecses 2002: 143).

8. CONTROLLER \& CONTROLLED (W) (Ny)

Schwarzkopf defeated Iraq (Kövecses and Radden 1998: 57).

9. CONTAINER \& CONTAINED (W) (Ny) (E) (No)

French aimer la bouteille "love the bottle" (Nyrop 1913: 199)

10. MATERIAL \& OBJECT (Ny) (E)

French_carton "cardboard" for "cardboard box" (Nyrop 1913: 201)

11. CAUSE \& EFFECT (Ny) (E) (No)

unlock the prisons for "let the prisoners free" (Norrick 1981: 87)

12. LOCATION \& PRODUCT (Ny) (E)

china (Kövecses and Radden 1998: 57)

13. POSSESSOR \& POSSESSED (E) (No)

the long straw starts for "the person with the long straw" (Norrick 1981: 98)

14. ACTION \& PARTICIPANT (P) (W) (Ny) (No)

to author a book (Kövecses and Radden 1998: 54)

15. PARTICIPANT \& PARTICIPANT (E) (No)

the pen is mightier than the sword for "the writer is mightier than the soldier" (Norrick 1981: 53) 
16. PIECE OP CLOTHING \& PERSON (P) (W) (Ny) (E) (No)

French une vieille perruque "an old wig" for "an old person" (Nyrop 1913: 196)

17. PIECE OF CLOTHING \& BODY PART (P) (W)

German Sohle "sole (of a shoe)" for "sole (of a foot)" (Waag 1901: 93)

18. SINGLE ENTITY \& COLLECTION (W)

German Imme "swarm of bees" for "bee" (Waag 1901: 92)

19. TIME \& ENTITY (E)

French un mardi-gras "a Shrove Tuesday" for "a disguised man" (Esnault 1925: 32)

20. OBJECT \& QUANTITY (E)

French un quart "a quarter" for "a tin of sardines in oil" (Esnault 1925: 32)

21. CENTRAL FACTOR \& INSTITUTION (No)

the press (Norrick 1981: 57)

22. POTENTIAL \& ACTUAL

Can you see him (Panther and Thornburg 1999: 339)?

23. HYPONYM \& HYPERONYM

the pill for "the contraceptive pill"

Most of these patterns are very general metonymies that were named regularly by many of our sources. Some, however, were either mentioned by only one source or refer to very specific entities such as pieces of clothing. While a number of these specific metonymies constitute a pattern in their own right, others will have to be subsumed under other, more general patterns, as Sections 3 to 6 will show. Finally, patterns (22) and (23) were not named by any of our initial sources. Still, they have received sufficient attention in recent years to be included in our inventory. Pattern (22), POtential \& ACTUal, was investigated in some detail by Panther and Thornburg (1999). It relates a potential situation to an actual one-an ability to its realization, for instance. Pattern (23), HYPONYM \& HYPERONYM, allows a hyponym to stand for its hyperonym or vice versa. It is mentioned as a type of metonymy by Kövecses and Radden (1998), but we will argue later that it actually constitutes a borderline case.

It should be mentioned with some insistence that this inventory of metonymical patterns is by no means meant to be an exhaustive classification of types of metonymy. Its purpose is not to present a complete and definitive list of metonymical types, but merely to define an empirical basis for the analytical exercise that we intend to pursue in the following sections. If we try to define the concept of "metonymy" (regardless of whether we aim at a unitary or a non-unitary definition), we need an observational 
basis of semantic shifts that are considered by most or many linguists to be examples of metonymy: these are the cases that should minimally be accounted for by the analysis.

Whereas most typologies of metonymy limit themselves to a similar enumeration of general patterns of contiguity and metonymy, we use such a list only as a starting point for the analysis. We believe, like Blank (1999), that linguistics has to look for a comprehensive cognitive framework that is able to cover and relate all these types of contiguity. Moreover, we are convinced that prototype theory presents us with such a framework. Although Barcelona (2002, 2003) and Dirven (2002) have applied prototype theory to distinguish metonymy from literal language or from metaphor (see Section 1), no one has yet tried to classify the metonymical patterns we just presented in a prototypical way. We will now put forward such a classification, based on the different types of contiguity that motivate all these metonymical patterns. In line with Seto (1999), we believe that contiguity, and thus metonymy, is present in both space and time. However, these two domains, which will be discussed in Sections 3 and 4 respectively, do not exhaust the metonymical patterns in our inventory. Two other domains, that of actions, events and processes on the one hand, and that of assemblies and collections on the other, will be added in Sections 5 and 6. In each of these four domains, different types of contiguity will motivate specific metonymical patterns from our inventory. ${ }^{5}$ This classification thus shifts the attention from the domains themselves to the contiguous relationships within these domains.

\section{Contiguity in the spatial and material domain 6}

Contiguity has always constituted the definitional core of metonymy, albeit in different forms (see Section 1). In our prototypical classification of conceptual contiguity, it seems intuitively straightforward to postulate spatial or material contiguity as the prototypical core. Metaphor theory has shown that space is a basic domain in our conceptualization: "We use ontological metaphors to comprehend events, actions, activities, and states. Events and actions are conceptualized metaphorically as objects, activities as substances, states as containers" (Lakoff \& Johnson 1980: 30). Hence, it seems a plausible idea to start our classification of metonymy with this basic spatial and material domain.

Our discussion of this domain will start with an enumeration of the patterns in our inventory that rely on spatial or material contiguity. Next, we will assume that the prototypical spatial contiguity relation is constituted by part-whole contiguity and that all other metonymical patterns are related to it. We will allow two relations, which will form the 


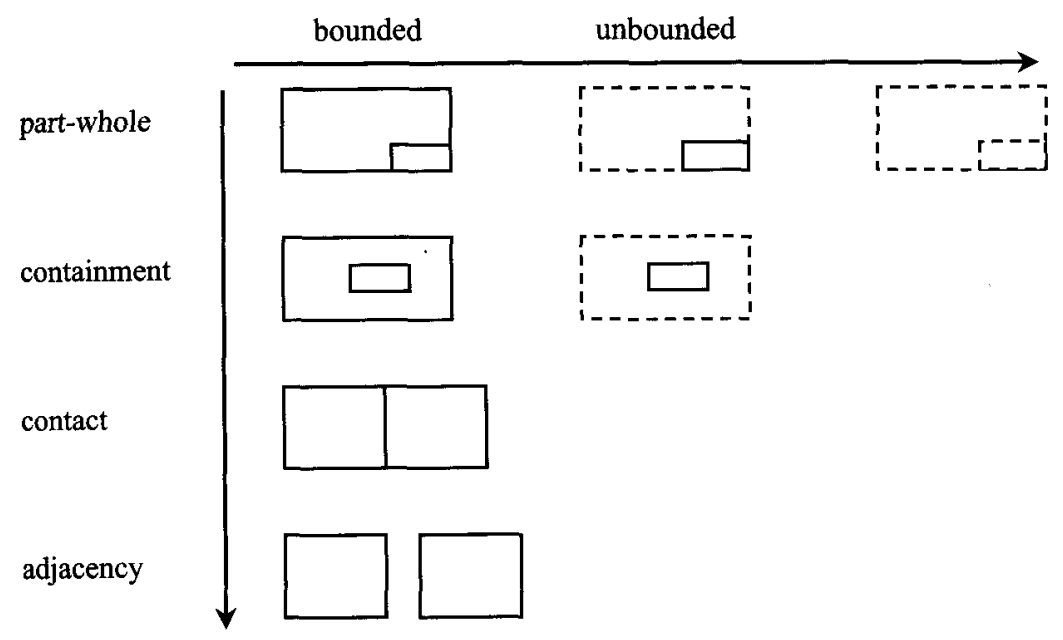

Figure 2. Metonymical patterns in the spatial and material domain: preview.

two dimensions that structure our classification of spatial and material metonymies. The first of these dimensions, "strength of contact", will allow us to extend the prototypical core in the direction of containment, contact and adjacency. The second dimension involves the "boundedness" of one or two of the contiguous entities; it allows us to conceptualize a bounded object as a part of an unbounded one. By combining these two dimensions, we will come to a classification of spatial metonymical patterns which will take the graphical form presented in Figure 2.

In order to delineate the category of spatial or material metonymies, we need to have a look at our inventory first. Six of the patterns it contains rely on purely spatial or material contiguity:

1. SPATIAL PART \& WHOLE

3. LOCATION \& LOCATED

9. CONTAINER \& CONTAINED

10. MATERIAL \& OBJECT

16. PIECE OF CLOTHING \& PERSON

17. PIECE OF CLOTHING \& BODY PART

These types can now be classified systematically in interrelated groups. An analysis of these subgroups is important because we will see later that similar subgroups may be distinguished when we move from this domain to other domains.

Seto (1999) claimed that the spatial domain contains three metonymical groups: whole-part, container-contained and adjacency. If we apply 
this analysis to our six metonymical patterns, three subgroups emerge: SPATIAL PART \& WHOLE and MATERIAL \& OBJECT represent part-whole relations, PIECE OF CLOTHING \& PERSON, PIECE OF CLOTHING \& BODY PART and LOCATION \& LOCATED are motivated by adjacency, and CONTAINER \& CONTAINED straightforwardly corresponds to Seto's (1999) containment pattern. Seto's (1999) classification is thus able to account for all the patterns from our inventory. Nevertheless, whereas Seto (1999) classifies these metonymies into three separate and largely unrelated groups, it is also possible to view them from a prototypical perspective as being more closely related. We will do this by relying on the different types of contiguity that they are motivated by.

SPATIAL PART \& WHOLE. The prototypical core of contiguity is formed by, we believe, part-whole relations. Tversky and Hemenway (1984) and Kövecses and Radden (1998), among others, have shown that parts and wholes are very basic categories in our conceptualization of the world. Kövecses and Radden (1998: 49), for instance, note that "[t]hings, in particular physical objects, are typically conceived of as forming a gestalt with well-delineated boundaries and as internally composed of various parts". If we look at contiguity from a prototypical perspective, partwhole relations are therefore a good candidate for the core of the category. Here are some examples:

PART FOR WHOLE:

Tony Blair is the Prime Minister of England; sich einen eignen Herd gründen "to build one's own hearth" (Waag 1901: 86); Pfeffer "pepper" for "dish with pepper sauce" (Waag 1901: 91); un Peau-rouge "redskin" (Nyrop 1913: 193); We need some good heads on the project. (Kövecses 2002: 145)

WHOLE FOR PART:

George Bush is the president of America; We have to fill up the car; I took up the telephone for "I picked up the receiver"; aigrette "small heron" for "bundle of feathers" (Nyrop 1913: 196)

The frequency and familiarity of many of these examples indicate that SPATIAL PART \& WHOLE may indeed be situated at the core of the category.

CONTAINER \& CONTAINED. Part-whole relations like those above are closely related to the containment pattern. An example such as Tony Blair is the Prime Minister of England, for instance, can be explained in two ways: on the one hand, England is a part of the UK; on the other, it is also contained by it. In this case, a container is conceptualized as a 
(functional, almost experiential) whole, on the basis of the containment relation with its content, its part. The following examples represent some typical CONTAINER \& CONTAINED metonymies:

CONTAINER FOR CONTAINED:

I drank a glass too many; aimer la bouteille "love the bottle" (Nyrop 1913: 199); un nid babillard "a chirping nest" (Nyrop 1913: 198); Platte "dish" (Waag 1901: 95); Mörtel "barrel" for "mortar" (Waag 1901: 95) CONTAINED FOR CONTAINER:

The milk tipped over. (Norrick 1981: 58); dépôt "deposit" for "depot" (Nyrop 1913: 200); Mappe "map" for "file" (Waag 1901: 95); Eingeweide "food eaten by grazing animals" for "intestines" (Waag 1901: 95)

The precise relation between PART \& WHOLE and CONTAINER \& CONTAINED seems to be that of a continuum that can be described in terms of "strength of contact". This is an intuitive notion that refers to the strength of the relation between the two entities involved. In part-whole constellations, this relation is at its strongest. England cannot normally be physically separated from the UK, just like heads cannot be separated from people without the application of brute force. In the case of containment, however, this relation is a little looser: mostly the content can easily be removed from its container. It is thus "strength of contact" that determines the place of a particular metonymy on the continuum.

LOCATION \& LOCATED. If we now allow this "strength of contact" to become a bit looser still, we arrive at a third metonymical pattern from our inventory: LOCATION \& LOCATED. In these metonymies, an entity is referred to by its location or vice versa:

LOCATION FOR LOCATED:

das ganze Haus wurde aus dem Schlaf geschreckt "the whole house was started out of its sleep" (Waag 1901: 96); die ganze Stadt lacht darüber "the whole city laughs at it" (Waag 1901: 96); Kapelle "chapel" for "band", originally "singers and musicians in the chapel" (Waag 1901: 96-97); Frauenzimmer "room for the women in the household" for "women" (Waag 1901: 97); tout le théâtre l'a applaudi "the whole theatre applauded him" (Nyrop 1913: 198); Washington is negotiating with Moscow (Kövecses 2002: 143)

LOCATED FOR LOCATION:

Universität "fellowship" for "university building" (Waag 1901: 98); Welt "mass of people" for "world" (Waag 1901: 98); Hammer "hammer" for "workplace" (Waag 1901: 86); billard "billiards" for "room where billiards is played" (Nyrop 1913: 200); banque "bank where money-dealers 
are seated" for "table where money is traded" for "bank, the building where money is traded" (Nyrop 1913: 200)

These LOCATION \& LOCATED examples are somehow intermediate between containment and adjacency relations. Their relation with adjacency is obvious: the location is adjacent to the entities that are situated there. Yet, whereas adjacency merely involves two entities that are situated near one another, LOCATION \& LOCATED presupposes a place (not merely an entity) that serves as a reference point for the entities that are located there. The relation with containment is sometimes less clear. Often LOCATION \& LOCATED involves literal containment, as in das ganze Haus wurde aus dem Schlaf geschreckt. However, even in examples in which no literal container is present (such as die ganze Stadt lacht darüber), we can still descry a metaphorical relation of containment:

We project our in-out orientation onto other physical objects that are bounded by surfaces. (...) Rooms and houses are obvious containers. (...) But even where there is no natural physical boundary that can be viewed as defining a container, we impose boundaries-marking off territory so that it has an inside and a bounding surface-whether a wall, a fence, or an abstract line or plane" (Lakoff and Johnson 1980: 29-30)

In short, although LOCATION \& LOCATED at first sight seems to rely on adjacency relations only, it is better to situate it in between adjacency and containment.

ENTTTY \& ADJACENT ENTTYY. The logical next step in the continuum constituted by the weakening of the "strength of contact" dimension consists of adjacency relations, where strength of contact is at its loosest. By this final extension of the continuum, we arrive at a general type of metonymical patterns that was not explicitly mentioned in our inventory, but that certainly exists. Two patterns from our initial list, PIECE OF CLOTHING \& PERSON and PIECE OF CLOTHING \& BODY PART, are merely specific manifestations of this more general type. We will call this type ENTITY \& ADJACENT ENTITY.

Whether concrete metonymies belong to adjacency or real contact often depends on interpretation. PIECE OF CLOTHING \& PERSON and PIECE OF CLOTHING \& BODY PART both seem to be motivated by contact contiguity. Other cases, however, seem to rely more on adjacency. Tafelrunde "round table", for instance, does not only refer to a piece of furniture, but also to the people sitting around it, and Liedertafel "table of songs" can serve as a name for a choir. Similarly, Tross and Pack, German for the luggage of an army, also refer to the army personnel, and more generally to someone's followers. These examples (from Waag 1901) are thus 


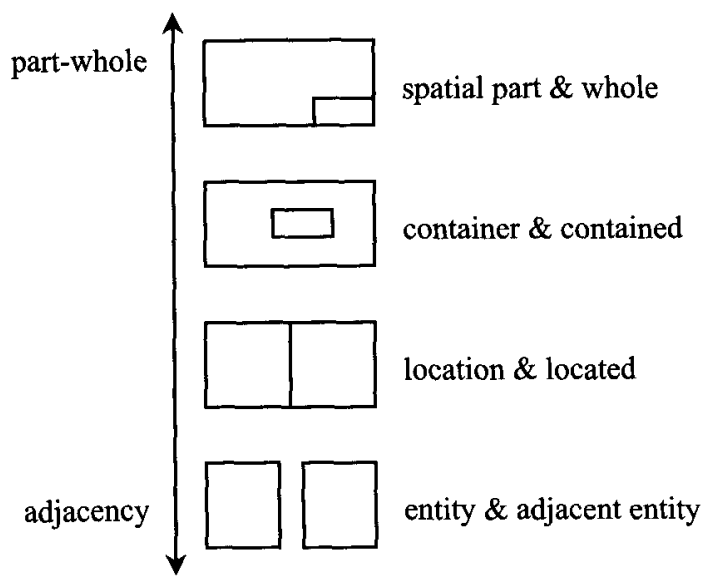

Figure 3. The continuum of "strength of contact".

situated at the bottom of our continuum, which so far takes the form given in Figure 3.

MATERIAL \& OBJECT. The classification of spatial and material metonymies in Figure 3 ignores one pattern from our initial list: MATERIAL \& OВJECT. In the literature on metonymy, this pattern is often subsumed under PART \& WHOLE. This is in line with Kövecses and Radden's (1998: 51) reasoning: "Substances may be conceived of as parts which constitute or make up things, in particular physical objects". Schofer and Rice (1977: 140), too, claim that "both on the semantic-iron is a feature of sword-and the referential levels-the sword is made of iron-there is a relationship of inclusion". There is thus reason enough to locate these metonymies together with SPATIAL PART \& WHOLE at the upper end of our continuum.

Still, we believe that there is a characteristic difference between these two metonymical patterns that needs to be spelled out. Let us first have a look at some examples to clarify the point:

OBJECT FOR MATERIAL:

There was cat all over the road (Kövecses \& Radden 1998: 51); hermine "ermine" (Nyrop 1913: 197); des gants de chevreau "goat gloves" for "goatskin gloves" (Nyrop 1913: 197)

MATERIAL FOR OBJECT:

carton "cardboard" for "cardboard box" (Nyrop 1913: 201); verre "glass" (Nyrop 1913: 201); fer "iron" for "instrument made of iron" (Nyrop 1913: 202); cuivre "brass" for "brass instruments" (Nyrop 1913: 202) 
OBJECT FOR MATERIAL + MATERIAL FOR OBJECT:

castor "beaver" for "beaver (fur)" for "hat of beaver fur" (Nyrop 1913: 201); loutre "otter" for "otter (fur)" for "hat of otter fur" (Nyrop 1913: 201)

As these examples show, the basic difference between SPATLAL PART \& WHOLE and MATERIAL \& OBJECT lies in the "boundedness" of the contiguous entities. In the former, the two entities are bounded, whereas in the latter, the material is unbounded. Most researchers, however, ignore this difference and classify the substance as a part of the object. Still, it would be at least as plausible to look at things the other way round, i.e. to see the bounded object as a part of the unbounded substance. For one, a substance is not really a part of a material entity, because the object may be completely made of this substance. Moreover, even if iron were a part of a sword, it is still different from more straightforward parts such as the handle or the blade, and the former type of metonymy should therefore be distinguished clearly from the latter more simple part-whole relationship. Finally, our classification of the substance as a whole can also be observed in other constructions, such as the German partitive genitive. In these cases, the substance is depicted as an unbounded resource, from which smaller quantities can be "individuated": eine Summe Geldes, "a sum of money", ein Liter dieses guten Weines, "a liter of this good wine".

If we thus see the substance as the whole and the object as a part, we can easily see in what way MATERIAL \& OBJECT is distinct from SPATIAL PART \& WHOLE: the "whole" in the latter pattern is a bounded entity, whereas in the former it is unbounded. This means that, perpendicular to the continuum described in the previous pages, two types of contiguity can be discerned. If both entities are bounded, we may speak of partwhole contiguity in the strict sense. If the whole is unbounded, we speak of a "loose". form of contiguity or, more to the point, individuation. This variation in boundedness constitutes a second basic dimension along which our prototypical core of part-whole relations can be extended.

Two questions now arise that could lead to further extensions of the variational structure that we have so far uncovered. First, could the shift from bounded to unbounded entities be carried even further, to the extent that we might come across examples of individuation that involve both an unbounded whole and an unbounded part? If we consider an example like chocolate, such cases would certainly seem to exist: chocolate does not only refer to the substance that is made from cacao beans, but also to a drink that is made from the substance in question by dissolving it in milk or water, i.e. to a drink that contains the substance. The substance is part of the drink, but both are unbounded entities. 


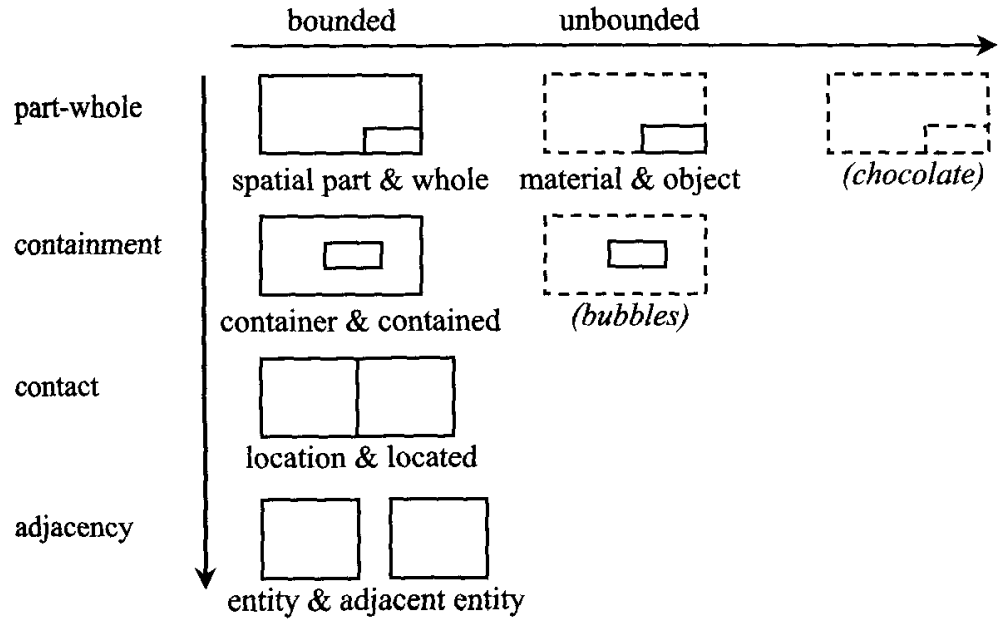

Figure 4. Metonymical patterns in the spatial and material domain.

A second question to consider is whether the distinction between strict contiguity and individuation can be generalized to the rest of the continuum, i.e. to the first dimension, which was summarized in Figure 3. If "metonymy" is indeed a prototypically structured category, such interactions may certainly be expected, given that multidimensional covariation is typical of prototypicality. In the case of CONTAINER \& CONTAINED such an interaction may indeed be envisaged. The container would then have to be conceptualized as an unbounded material that contains smaller bounded entities, just like water contains minerals or impurities. A metonymy based on such a configuration would be the (informal) Dutch expression bubbels "bubbles", which can refer to the champagne that contains the bubbles: the bubbles are bounded, countable entities that are contained in the unbounded mass of champagne.

If we now combine the two dimensions, that of "strength of contact" on the one hand, and that of "boundedness" on the other, we arrive at the prototypical classification of spatial and material metonymies that is graphically represented in Figure 4.

Let us summarize. The prototypical core of contiguity in the spatial and material domain is constituted by SPATIAL PART \& WHOLE, in the upper left corner. This core can be extended into two directions. The vertical dimension of "strength of contact" takes it via CONTAINER \& CONTAINED and LOCATION \& LOCATED to ENTITY \& ADJACENT ENTITY. The horizontal dimension takes it into the direction of MATERIAL \& OBJECT. The combination of these two dimensions covers all the metonymical patterns from 
our inventory that we mentioned at the beginning of this section, together with some additional examples that do not belong to our initial base.

The prototypical nature of the analysis has two important consequences. First, we do not wish to exclude the possibility of defining alternatives to the model as we sketched it above. The very multidimensionality of prototypically structured categories, in fact, would seem to allow for different ways of analyzing the structure of the category. The important point we want to make is that metonymies in the spatial and material domain seem to be prototypically organized as a cluster of extensions around the core pattern of SPATIAL PART \& wHOLE. Two dimensions, the "strength of contact" between the two entities and their "boundedness", structure this cluster and relate more marginal patterns to the central ones. The precise way these relations are presented, however, depends on interpretation and probably allows for alternatives.

Second, in a prototypical classification, individual examples can often be related to several more general types at the same time. This characteristic, which we may call "multiple motivation", applies to many of the metonymies cited above. Hermine "ermine", for instance, and des gants de chevreau for "goatskin gloves" link up with SPATIAL PART FOR WHOLE as well as with OBJECT FOR MATERIAL, as the skin of an animal is a natural part of this animal. Further, we classified the metonymical patterns PIECE OF CLOTHING \& PERSON and PIECE OF CLOTHING \& BODY PART along with ENTITY \& ADJACENT ENTITY. They can, however, also be related to CHARACTERISTIC \& ENTITY or POSSESSOR \& POSSESSED, as we will see in the following sections. Similarly, the chocolate example could be ranged with the INSTRUMENT \& RESULT pattern that will be mentioned in Section 5. The theory of prototypicality does not force us to choose for one of these alternatives-it allows concrete examples to have multiple motivations.

\section{Contiguity in the temporal domain}

As we have already mentioned, our conceptualization of time is inextricably bound up with that of space. This relationship was noted by Kronasser (1952: 158), among others:

In der Vorstellungswelt der Völker sind ja Raum und Zeit völlig identisch, da es ja in der Praxis des täglichen Lebens weder ein Raumerlebnis ohne Zeit noch ein Zeiterlebnis ohne Raum gibt.

[in the conceptualized world of peoples, space and time are completely identi$\mathrm{cal}$, because in the practice of everyday life there exists neither an experience of space without time nor an experience of time without space] (Kronasser 1952: 158) 


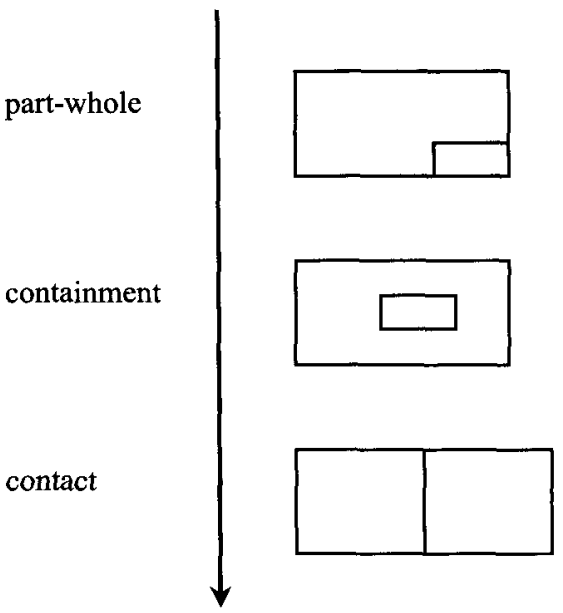

Figure 5. Metonymical patterns in the temporal domain: preview.

Many expressions, he noted, which are used both in a spatial and in a temporal way stem from the spatial domain: "Der Bedeutungswandel vom Räumlichen zum Zeitlichen ist überall eine Alltäglichkeit" [the meaning shift from space to time is ordinary everywhere]. Similarly, Lakoff and Johnson (1980) showed that time is conceptualized through metaphors of space. There are thus good reasons to explore whether the types of contiguity we identified in space are metaphorically reflected in the domain of time.

We will now try to substantiate this hypothesis with concrete patterns from our inventory. It will be shown that several spatial types of contiguity correspond to temporal patterns. As before, the core of the category will be constituted by PART \& WHOLE metonymies. In the temporal domain, this prototypical core can be extended into one direction: a loosening of the "strength of contact" dimension takes it over containment relations (TIME \& ENTITY) to contact (ANTECEDENT \& CONSEQUENT). It will thus become clear that the structure of the temporal field of application is closely related to its spatial counterpart. This observation will lead us to the classification of temporal metonymies previewed in Figure 5.

TEMPORAL PART \& WHOLE. TEMPORAL PART \& WHOLE, our metonymical pattern (2), corresponds straightforwardly to SPATIAL PART \& WHOLE: both its source and target are periods of time, and these stand in a partwhole relationship. As Waag (1901) documents, some German expressions of time have undergone a diachronic change along these lines and now refer to a larger stretch of time than they used to do. For instance, 
the Dutch and German morgen, "morning" or "tomorrow", no longes only refer to the morning of the next day: this "part" meaning was ex. tended, so that it now includes the whole next day. Similarly, German Sonnabend literally means "the evening before Sunday" but actually refers to Saturday as a whole. In Southern Germany, the expression Mittag "noon" also includes the afternoon. Tag "day" originally only referred to the period from dawn to dusk, but in its metonymical meaning of "twenty-four hours" it also includes the night. In short, just like their spatial counterparts, these metonymies pick out a part of a time period (such as the evening or the morning) in order to refer to the whole (the day).

TIME \& ENTITY. One step further along the "strength of contact" dimension, we find the contiguous relationship of containment. This relationship motivates the temporal pattern TIME \& ENTITY, metonymical pattern (19). It includes examples such as the following:

TIME FOR ENTITY:

'40-'45 changed the history of the world; 9-11 will never be forgotten; The sixties were very progressive; The next decades will be faced with important problems such as pollution and overpopulation; un mardi-gras "a Shrove Tuesday" for "a disguised man" (Esnault 1925: 32)

At the basis of all these examples lies a conceptualization of time as a container. Like a container, a time period can accommodate all kinds of things: ' $40-45$ and 9-11 refer to the events which took place at that time, while the sixties, the next decades and un mardi-gras refer to the people that live at a certain time or take part in certain festivities.

ANTECEDENT \& CONSEQUENT. Just like in the spatial domain, the dimension of "strength of contact" can now be extended even further in the direction of temporal contact. This kind of contiguity can be found in our conceptualization of two temporal entities that follow each other. One metonymical pattern from our inventory that meets these requirements is ANTECEDENT \& CONSEQUENT, pattern (4). It explains the shift of meaning that took place in the Greek word phobos. Originally, this word meant "flight", but it gradually came to stand for the antecedent of this action, viz. "fear". The Mittag example that we mentioned earlier could also be analyzed in a similar way: the shift from "high noon" to "afternoon" is a case of an ANTECEDENT \& CONSEQUENT pattern if the period of noon is not seen as part of the second half of the day, but as a distinct period preceding the afternoon. Both perspectives would seem to be possible-which is yet another indication for the possibility of multiple motivations in a prototypically structured category. 


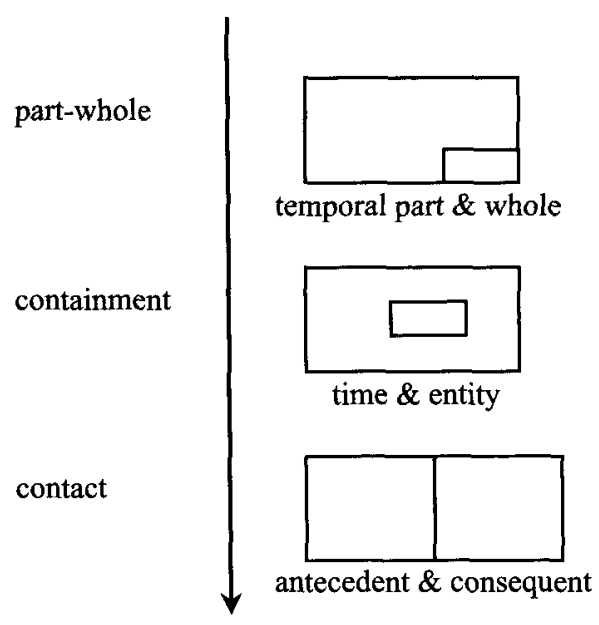

Figure 6. Metonymical patterns in the temporal domain.

The purely temporal domain of metonymical patterns, which is given in Figure 6, is not a very productive one. Even though its structure clearly mirrors that of the spatial domain, many of the examples above represent historical evolutions that present language users do not recognize as metonymical anymore. Moreover, the pattern ANTECEDENT \& CONSEQUENT appears to extend beyond the temporal domain. Our Greek example phobos includes an action rather than a purely temporal entity, and the relationship between its source and target is not merely temporal, but also causal. It is therefore not surprising that a combination of the spatial and temporal types of contiguity gives rise to a third, very productive domain-that of actions, events and processes.

\section{Contiguity in actions, events and processes}

The temporal domain of contiguity that we have just discussed is metaphorically related to the spatial domain, since the spatial entities were straightforwardly replaced by temporal ones. Up to a point, the next domain of contiguity combines elements from these two sources: it contains relationships between the temporal entities of actions, events, and processes on the one hand, and their mostly spatial participants on the other. Thanks to this combination of sources, its structure is again richer than that of the purely temporal domain, as Figure 7 indicates. Not only does the dimension of "strength of contact" extend beyond "contact" to "adjacency"; the second dimension of "boundedness" again plays a major role. 


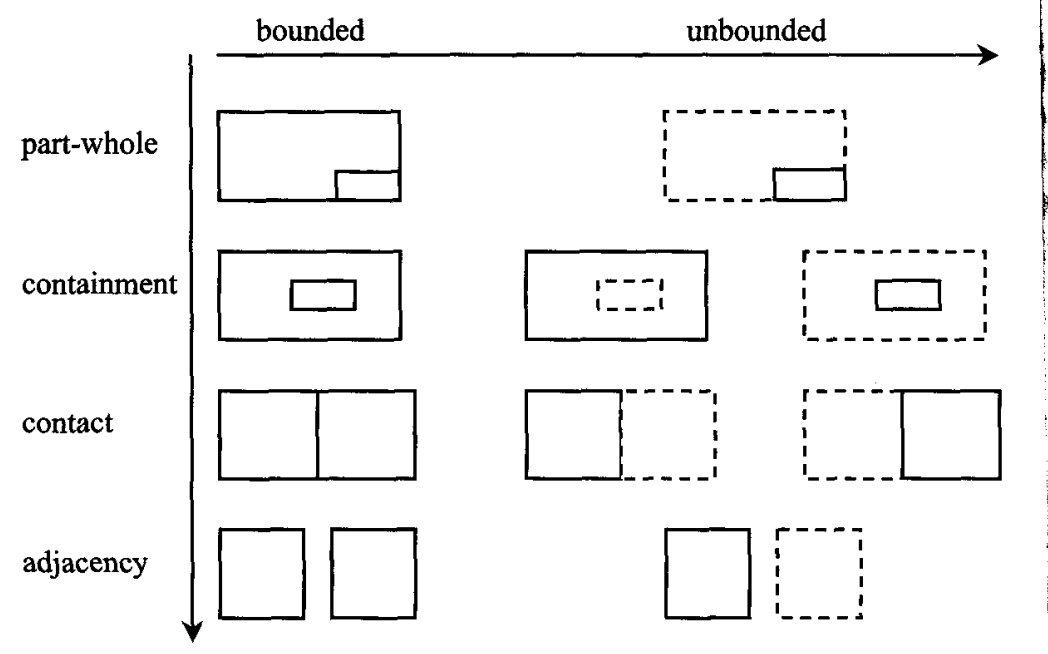

Figure 7. Metonymical patterns in actions, events and processes: preview.

SUBEVENT \& COMPLEX EVENT. The prototypical structure of the domain of actions, events and processes again has its core in part-whole relations between bounded entities. Instead of relating two spatial entities or two periods of time, however, the metonymical pattern SUBEVENT \& COMPLEX EVENT comprises two actions, events or processes, one of which is conceptualized as a part of the other. This metonymical pattern thus allows us to pick out one subevent of a more complex event in order to refer to this more complex event. As the following examples show, this pattern is omnipresent in everyday language:

SUBEVENT FOR COMPLEX EVENT:

How did you get to the party? (Lakoff 1987: 78)

- I stepped into a car.

- I started to come.

- I drove.

- I borrowed my brother's car.

- I just stuck out my thumb.

- I hopped on a bus.

In this example, the listed replies do not straightforwardly answer the initial question. The first two answers are possible in a language such as Ojibwa. Both of these metonymies foreground a subevent at the beginning of the more complex event. The other four answers are also acceptable in English, even though they all name a subevent instead of the complex event that they refer to. Some similar examples are Mother is cooking 
potatoes (Kövecses 2002: 153) and I have to grade hundreds of papers (Kövecses 2002: 153). Parallel to the previous instances, cooking is only one action in the more complex process of preparing food, just like grading papers does not simply involve writing down marks. All these examples thus rely on the same ability to conceptualize simplex activities as parts of more complex wholes.

Moreover, this pattern also includes those instances of metonymy which Waag (1901) and Paul (1970) termed SYMBOLIC SUBEVENT FOR COMPLEX EVENT. Symbolic actions such as "putting a king on the throne", or "leading a girl to the altar" are all subevents of the more complex event they refer to. The following examples may therefore be identified as special cases of the metonymical pattern under investigation:

SUBEVENT FOR COMPLEX EVENT:

auf den Thron setzen "put on the throne" (Waag 1901: 102); ein Mädchen zum Altar führen "lead a girl to the altar" for "marry" (Waag 1901: 101); den Handschuh aufnehmen "take up the gauntlet" (Waag 1901: 102); die Hand auf etwas legen "lay hands on something" (Waag 1901: 101); die Hände in den Schoss legen "put your hands in your lap" for "sit back" (Paul 1970: 99)

In short, we have now found a third type of entities that may stand in contiguous part-whole relationships to each other. In addition to the spatial and purely temporal patterns that we observed in the previous sections, it is now clear that actions, events and processes as well may act as parts and wholes.

ACTION/EVENT/PROCESS \& STATE. Interestingly, this part-whole relationship also exists between actions and states. In sentences such as Mary speaks Spanish, John smokes, or Harry drinks, the activities of speaking, smoking and drinking metonymically stand for the states of which they are a part. Speaking, for instance, is only one sub-activity of the general knowledge of a language. Similarly, the references to the actions of smoking and drinking actually mean that John is a smoker and Harry an alcoholic. Since actions, events and processes are temporally bounded, while states are unbounded, these examples instantiate the phenomenon that we have called individuation (see Section 3 ). ${ }^{7}$

A similar analysis can be applied to those metonymies that have formerly been called POTENTIAL \& ACTUAL, i.e. pattern (22) in our inventory. These metonymies have been studied in detail by Panther and Thornburg (1999). For instance, in She was able to finish her dissertation, the person's ability, which is unbounded in time, stands for the actual occurrence of a situation in which she passed the test: She finished her dissertation. 
Similarly, in indirect speech acts such as Can you let me in? the speaker is not interested in the listener's ability to open the door, but asks the listener to do so. POTENTIAL \& ACTUAL metonymies such as these are very frequent, as the following examples (from Panther and Thornburg 1999) show:

POTENTIAL FOR ACTUAL:

perceptual events: Can you see him?

mental states and processes: Mary can't believe that Steve is guilty, but 1 can.

hedged performatives: I can give you my word that he is not at home.

indirect speech acts: When you come to Budapest, I can be your translator.

extra-linguistic actions: I can come to your party on Friday.

character dispositions: He can be very unfriendly.

acquired skills: Mary can speak five languages.

These constructions all involve two situations: a potential, unbounded one and an actual, bounded one. Therefore they can be analyzed as STATE FOR ACTION.

ACTION/EVENT/PROCESS \& PARTICIPANT. In the previous sections, we subsequently observed that the prototypical core of part-whole relations could be extended along the continuum of "strength of contact" in the direction of containment. This seems to be the case in the domain of actions, events and processes as well. In ACTION/EVENT/PROCESS \& PARTICIPANT, pattern (14), the container is not a spatial or purely temporal entity, but an action, event or process, with its participants as its contents. This action is a "functional" container (cf. Vandeloise 1986): ${ }^{8}$ even though most participants exist before as well as after the action, they can still be conceptualized as the action's contents.

Since an action can have a whole range of participants, the pattern ACTION/EVENT/PROCESS \& PARTICIPANT is a very productive one. The participant entities involved include its agent, its patient, its location, its time and its instrument. Because actions are typically referred to by verbs, and participants by nouns, it is not surprising that many examples of this metonymical pattern are either verbifications or nominalizations. The grammatical phenomena that go hand in hand with the metonymical shifts certainly deserve further investigation, but will not be treated here.

The most prototypical participant of an action/event/process is probably the agent. This active participant can metonymically refer to the action he performs, or vice versa: 
AGENT FOR ACTION/EVENT/PROCESS:

to butcher the cow (Kövecses and Radden 1998: 54); to author a book (Kövecses and Radden 1998: 54)

ACTION/EVENT/PROCESS FOR AGENT:

snitch (slang: "act of informing" for "informer") (Kövecses and Radden 1998: 54); aide "act of helping" for "helper" (Nyrop 1913: 215); pince "act of pinching" for "pincers" (Nyrop 1913: 215); assistance "act of attending" for "public" (Nyrop 1913: 218); Regierung "government" (Waag 1901: 106)

In the first group of examples, it is the agent that stands for the action: it is the butcher that butchers and the author that authors. In the second group, the action stands for its agent: it is, for example, the government that performs the act of governing.

The second adjacency relation is constituted by an action/event/ process and its patient:

ACTION/EVENT/PROCESS FOR PATIENT:

achat, first "act of buying" then "purchase" (Nyrop 1913: 221); vitrage "act of putting in a pane of glass" for "window pane" (Nyrop 1913: 222); peinture "act of painting" for "painting" (Nyrop 1913: 221); envoi "act of sending" for "package" (Nyrop 1913: 215); Versammlung "collection" (Paul 1970: 100); Vereinigung "association" (Paul 1970: 100); Anlage "act of laying out" for "public garden, park" (Waag 1901: 107)

The French word achat originally referred to the action of buying things before the metonymical meaning "the things bought" was added. Vitrage underwent a similar evolution: it can now refer to the patient of the original action as well. The other examples can be explained in a similar way. ${ }^{9}$

Location is the third participant entity that can enter into a metonymical relation with an action/event/process. For instance, in French, marche used to denote the act of trading, but its meaning changed into that of English market, location of trading (Nyrop 1913: 223). Here are some other examples:

ACTION/EVENT/PROCESS FOR LOCATION:

Gang "act of walking" for "corridor" (Waag 1901: 108); Weg "act of moving" for "road" (Waag 1901: 108); Tritt "act of treading" for "step" (Waag 1901: 108); passage "act of passing" for "passage" (Nyrop 1913: 216); sortie "act of leaving" for "way out" (Nyrop 1913: 216); repos "act of resting" for "bed" (Nyrop 1913: 216); demeure "act of living" for "house" (Nyrop 1913: 216)

The reverse metonymy, in which the location is the source and an action/ event/process the goal, is attested in the following examples: 
LOCATION FOR ACTION/EVENT/PROCESS: A lot of Americans protested during Vietnam. (Frisson and Pickering 1999: 1370); America doesn't want another Pearl Harbor. (Kövecses 2002: 143); Let's not let El Salvador become another Vietnam. (Kövecses 2002: 144); Watergate changed our politics. (Kövecses 2002: 144)

The Americans obviously did not protest against the country of Vietnam, but against the war in Vietnam, and the location consequently refers to the action situated there. The other examples are constructed in a similar way.

The fourth participant entity to enter into a metonymy with its action/ event/process is time. Time, often seen as the metaphorical counterpart of location (cf. supra) can thus serve as the metonymical source for the action taking place at that moment, or vice versa:

ACTION/EVENT/PROCESS FOR TIME:

tonte "act of shearing" for "shearing season" (Nyrop 1913: 216); la saison first "act of sowing" then "season" (Nyrop 1913: 223); fenaison "act of haymaking" for "haymaking season" (Nyrop 1913: 223); fauchaison "act of mowing" for "mowing time" (Nyrop 1913: 223); cueillaison "act of picking" for "picking season" (Nyrop 1913: 223)

TIME FOR ACTION/EVENT/PROCESS:

to summer in Paris (Kövecses and Radden 1998: 55)

All the (agricultural) actions above refer to the season or period in which they are performed. By contrast, if one "summers in Paris", one lives in Paris during summer, the season that metonymically refers to the action.

The fifth and last participant entity that leads to a productive metonymical pattern is the instrument with which the action/event/process is performed. Skiing, for instance, is an action that obviously requires skis as instruments, and, similarly, hair cannot be shampooed without the necessary instrument, shampoo. It is because of their indispensable presence that these instruments can stand for the action in which they are used:

INSTRUMENT FOR ACTION/EVENT/PROCESS:

to shampoo one's hair (Kövecses and Radden 1998: 54); to ski (Kövecses and Radden 1998: 54)

ACTION/EVENT/PROCESS FOR INSTRUMENT:

Andenken "act of remembering" for "keepsake" (Waag 1901: 109); Letze "act of leaving" for "farewell drink/gift/..." (Waag 1901: 109)

All in all, the metonymical pattern ACTION/EVENT/PROCESS \& PARTICIPANT appears to be a constellation of five more specific metonymical 
patterns, depending on the participant entity that is involved. This entity can be the agent, the patient, the location, the time or the instrument of the action, event or process. ${ }^{10}$ All these minor patterns can be interpreted as a result of metaphorical containment relations in the spatio-temporal domain.

Because of the productivity of this metonymical pattern, it is no surprise that it can also involve unbounded entities. This happens in two cases. First of all, it is possible that the participant is an unbounded entity, as in the following examples:

ACTION/EVENT/PROCESS FOR PATIENT: Sprache "act of speaking" for "language" (Waag 1901: 107-108)

ACTION/EVENT/PROCESS FOR INSTRUMENT: Nahrung "act of feeding" for "food" (Waag 1901: 109)

Second, instead of a bounded action, event or process, the metonymy can also involve an unbounded state and its participants, as in these examples:

STATE FOR LOCATION: Gehorsam "obedience" for "location where people are taught to obey", i.e. "prison" (Waag 1901: 109)

STATE FOR INSTRUMENT: connoissances "state of knowing someone" for "gifts to knights from their ladies (Middle Ages)" (Nyrop 1913: 215)

These metonymies thus show that the containment pattern of ACTION/ EVENT/PROCESS \& PARTICIPANT can be extended along the dimension of boundedness.

CAUSE \& EFFECT. A further loosening of the strength of contact between the source and the target takes us again from containment to contact contiguity. This contact relation between two actions, events or processes lies at the basis of metonymical pattern (11), CAUSE \& EFFECT, which is closely related to the purely temporal ANTECEDENT \& CONSEQUENT (see Section 4). In the following cases, the preceding action is the cause of the subsequent one:

CAUSE FOR EFFECT:

unlock the prisons for "let the prisoners free" (Norrick 1981: 87); That was a slap in the face for him.

EFFECT FOR CAUSE:

empty a glass for "drink a glass" (Norrick 1981: 87); er fährt auf "he starts to his feet" for "he is angry" (Waag 1901: 99); staunen "stare" for "be astonished" (Waag 1901: 100); das entsetzt mich "it un-seats me" for "it alarms me" (Waag 1901: 100) 
In contrast to SUBEVENT \& COMPLEX EVENT, the two actions/events/ processes here have the same status: there is no necessary or obvious part-whole relationship between them. Rather, their relationship corresponds to that of two neighbouring entities in the spatial domain. In the first examples, the cause stands for its effect, while in the other metonymies, the metonymical targets are the cause of their sources.

As before, CAUSE \& EFFECT metonymies can involve unbounded entities as well as bounded ones. In the CAUSE FOR EFFECT examples below, an unbounded cause ("cowardess", "charity", "malice") stands for a bounded effect ("act of cowardess", "a small amount of money" and "trick"). In the EFFECT FOR CAUSE examples, an unbounded effect ("fragrance", "lustre", "light") stands for its bounded cause ("perfume", "chandelier", "lamp").

CAUSE FOR EFFECT:

lâcheté "cowardess" for "act of cowardess" (Nyrop 1913: 225); demander la charité "ask for charity" (Nyrop 1913: 226); malice "malice" for "trick" (Esnault 1925: 32)

EFFECT FOR CAUSE:

parfum "perfume" (Nyrop 1913: 207); lustre "luster" for "chandelier" (Nyrop 1913: 207); lumière "light" for "lamp" (Esnault 1925: 31)

These metonymies thus illustrate that in this domain, the unbounded dimension stretches further than before, since it now includes contact contiguity as well.

PaRTICIPANT \& Participant. The lower end of the continuum in the spatial domain was occupied by the contiguous relationship between two entities that are situated near one another. We believe that this description corresponds to the relationship between two participants of an action. This relationship is looser than the types of contiguity above. First, the participants are only indirectly related via the action, event or process in which they both participate. Second, although this relationship also involves causality, just like CAUSE \& EFFECT, this time it has a weaker form. This causality is most obvious in those patterns that include the agent and the patient of an action, but also plays a role in INSTRUMENT \& RESULT and LOCATION \& PRODUCT.

Although the strength of contiguity is thus rather weak here, this metonymical pattern is very frequent. This may be due to the fact that both temporal and spatial contiguity play a role. On the one hand, PARTICIPANT \& PARTICIPANT certainly has a spatial component: typically, the two participants are spatial entities that are related by spatial contiguity. On the other hand, however, it is the temporal action, event or process that conceptually keeps them together. That is why, for instance, china 
can still be called china even when the spatial adjacency does not exist anymore; the temporal tie between the product and the location is still present in our minds. This pattern thus constitutes a clear case of multiple motivation. Moreover, since we have already mentioned that participants may be unbounded, it is not surprising that the present pattern can be extended along the axis of boundedness.

PARTICIPANT \& PARTICIPANT includes five important subpatterns: CONTROLLER \& CONTROLLED, pattern (8), POSSESSOR \& POSSESSED, pattern (13), PRODUCER \& PRODUCT, pattern (7), LOCATION \& PRODUCT, pattern (12), and INSTRUMENT \& RESULT, which was not present in our initial inventory but which needs to be added, as we will see presently. Three of these subpatterns result from the adjacency relation between the agent and the patient. Depending on the type of action/event/process, this contiguity relation leads to CONTROLLER \& CONTROLLED, POSSESSOR \& POSSESSED or PRODUCER \& PRODUCT.

For one, the agent can be the controller of the patient, as in the following examples:

\section{CONTROLLER FOR CONTROLLED:}

Schwarzkopf defeated Iraq. (Kövecses and Radden 1998: 57); Nixon bombed Hanoi. (Kövecses 2002: 143); Ozawa gave a terrible concert last night. (Kövecses 2002: 144)

CONTROLLED FOR CONTROLLER:

The Mercedes has arrived. (Kövecses and Radden 1998: 57); That's a cautious lorry.

Contrary to what the first example may literally say, Schwarzkopf did not defeat Iraq on his own. Rather, it was the army controlled by Schwarzkopf that did the job. Similarly, Ozawa did not give concerts on his own; the terrible performance was given by the orchestra he conducted. The last example, finally, does not intend to convey that a certain car has arrived, but rather that the person who sits in the car and controls it is now present.

Other metonymies that can also be categorized under CONTROLLER \& CONTROLLED are those in which a certain entity or salient attribute thereof metonymically stands for the person by whom it is "controlled". In the piano is ill today, the controlled entity (the piano) stands for the person that usually plays (and hence controls) it. Analogous to this example, a large eater can be called une bonne fourchette [a good fork] in French (Nyrop 1913: 192) on the basis of the control relation between the eater and the cutlery.

A second possible instantiation of the agent-patient relation is one in which the patient is possessed by the agent. ${ }^{11}$ This relation serves as a motivation for metonymies such as the following: 
POSSESSOR FOR POSSESSED:

This is Harry for "Harry's drink" (Kövecses and Radden 1998: 57) POSSESSED FOR POSSESSOR:

He married money for "someone who has money" (Kövecses and Radden 1998: 57); She married power for "someone who has power" (Kövecses 2002: 155); the long straw starts for "the person with the long straw" (Norrick 1981: 98)

Harry, the name of the possessor of the drink, here refers to this drink, and someone who marries money obviously does not marry a pile of bank notes, but rather conceals his intentions by marrying someone who possesses heaps of money. This latter example moreover indicates that PARTICIPANT \& PARTICIPANT can also involve unbounded entities.

In a third instantiation of the agent-patient relationship, the agent is the producer of the patient. These metonymies were already present in our inventory as metonymical pattern (7). In all the following examples, the product is named after the producer, or vice versa:

\section{PRODUCER FOR PRODUCT:}

a Ford (Kövecses and Radden 1998: 56); I'm reading Shakespeare. (Kövecses 2002: 143); She loves Picasso. (Kövecses 2002: 144); Does he own any Hemingway? (Kövecses 2002: 144); du macadam "macadam" (after MacAdam) (Nyrop 1913: 205)

PRODUCT FOR PRODUCER:

coucou "cuckoo" (Nyrop 1913: 208); French turlut "meadow pipit" (Nyrop 1913: 208); goddam "goddamn" for "Englishman" (Nyrop 1913: 210)

A well-known metonymy of this type is ARTIST FOR HIS WORK, as in $\mathrm{He}$ doesn't like Picasso, or He likes to read Hemingway. "Producers of highly outstanding 'products' of a culture like artists, scientists and inventors receive particular metonymic attention" (Kövecses and Radden 1998: 57), and the name Picasso can thus refer to a painting or drawing made by this artist, just like Hemingway can refer to a book as well as to its author. Kövecses and Radden (1998) claim that this metonymical relation is irreversible. Still, there are for instance bird names, such as English cuckoo or French turlut "meadow pipit" (Nyrop 1913: 208), which name the producer after its product. The reverse relationship thus seems to be possible after all.

A second adjacency relation can be observed between the location of an action/event/process and its patient. This metonymical pattern was taken up in our inventory as pattern (12), LOCATION \& PRODUCT. 
LOCATION FOR PRODUCT:

mokka (Kövecses and Radden 1998: 57); java (Kövecses and Radden 1998: 57); china (Kövecses and Radden 1998: 57); du carrare "carrara" (Nyrop 1913: 205); du camembert "camembert" (Nyrop 1913: 205); du bordeaux "Bordeaux" (Nyrop 1913: 205)

In all these cases, the place where a certain product originates from or is produced comes to stand for the product itself. As an alternative possibility, we can also analyze these examples as a metonymical chain. This chain combines LOCATION FOR LOCATED and PRODUCER FOR PRODUCT: the location refers to the people that live there, and these people then stand for the products they manufacture. In this analysis, the link with causality is particularly clear. The reverse relation is rare, but not impossible, again contrary to Kövecses and Radden's (1998) findings. A counterexample to their claim can be found in Madeira:

Un exemple curieux nous est fourni par le nom portugais Madeira, tiré de madeira (...), bois de construction; comme l'île fournissait beaucoup de madeira, elle en reçut le nom.

[A curious example is furnished by the Portuguese name Madeira, derived from madeira ..., construction wood; as the island supplied much madeira, it took on its name] (Nyrop 1913: 208).

Note that, since products are typically unbounded, these examples again show that PARTICIPANT \& PARTICIPANT can be extended along the axis of boundedness.

Finally, an example such as whistle indicates that the instrument of an action can enter into a metonymical relation with the patient or result of this action. This metonymical pattern of INSTRUMENT \& RESULT was not included in our inventory, as pre-structuralism mainly treated it as a subtype of PRODUCER \& PRODUCT (see e.g. Nyrop 1913: 206). Again, the reverse relation is much less frequent, but seems to be possible, as in this example from Funck-Brentano (quoted by Nyrop 1913: 207): when she wanted to take revenge on her enemies, his marquise of Brinvilliers said, "qu'il y avait dans cette boîte bien des successions" [that there were some successions in this box]. The box she refers to does not contain the successions themselves, but rather the instrument, the poison, which will help to bring them about. Still, metonymies such as this one appear to be very infrequent, and the literary source of this example may point to its artificial character. Another marginal example is The 8:40 just arrived (Kövecses 2002: 145). Here the moment of the action stands for the agent, the train arriving at 8:40. This metonymy can thus be analyzed as TIME FOR AGENT. PARTICIPANT \& PARTICIPANT thus contains a wide variety of 


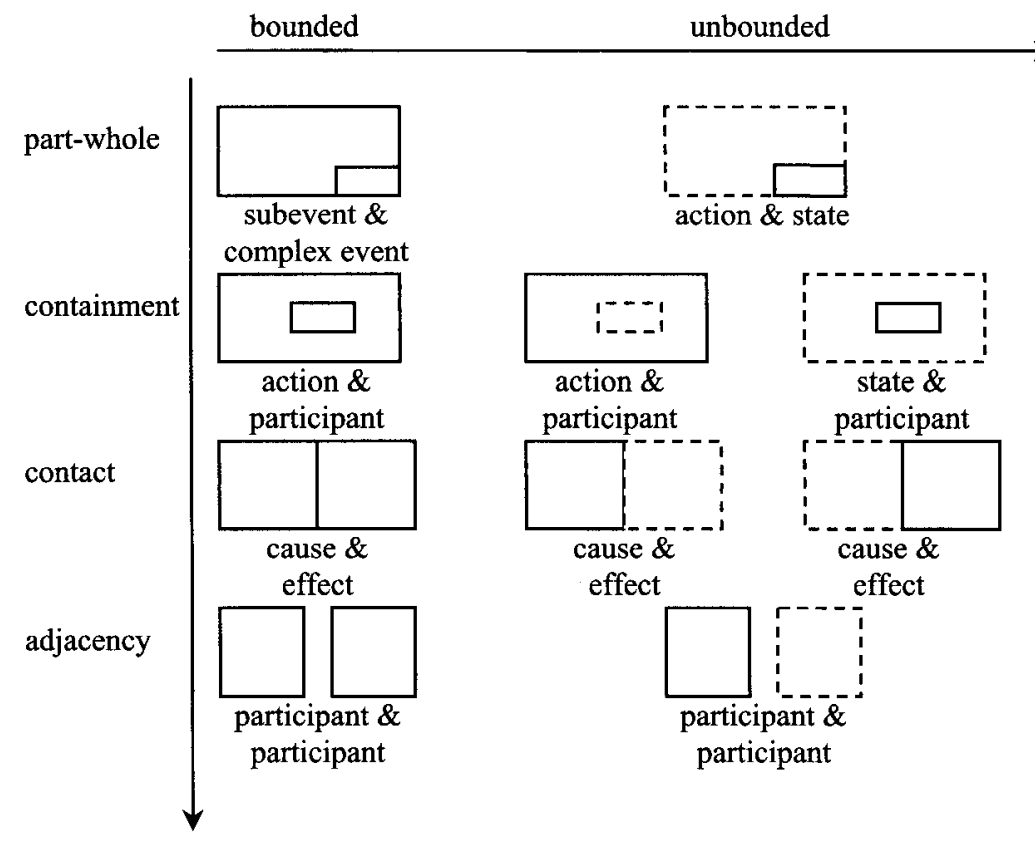

Figure 8. Metonymical patterns in actions, events and processes.

typical and less typical metonymies that are all motivated by the same type of contiguity.

To summarize, the structure of the metonymical patterns that we find in the domain of actions, events and processes closely corresponds to the organization of the patterns in the spatial and temporal domains. The overall structure is presented in Figure 8, which repeats the structure of Figure 7. As in the previous sections, the core of the domain is constituted by part-whole relations. The dimension of "strength of contact" relates this core to containment, contact and adjacency relations. The second dimension takes us from metonymies with bounded entities to those that involve unbounded states or participants.

Again, alternative conceptualizations are not precluded by our model. As we discussed in note 10, MANNER FOR ACTION metonymies, for instance, may be classified as PARTICIPANT FOR ACTION, or as CHARACTERISTIC FOR ENTITY. As always, the preferred conceptualization of MANNER will be the decisive factor. CAUSE \& EFFECT presents a further example. In metonymies such as secourir, "rush forward" for "help" (Nyrop 1913: 213), or er fährt auf, "he starts to his feet" for "he is angry", (Waag 1901: 99) one action can easily be conceptualized as a part of the other. Rushing 
forward then becomes part of the helping event, and starting to one's feet is only one aspect of anger. By adopting this conceptualization, these metonymies turn from CAUSE \& EFFECT into COMPLEX EVENT \& SUBEVENT. In addition, the POTENTIAL FOR ACTUAL metonymies we mentioned earlier can also be analyzed as CAUSE FOR EFFECT: A person's ability to do something can be conceptualized as (part of) the cause of this action. Finally, Kövecses's (2002) example The 8:40 just arrived can be classified as TIME FOR AGENT or as CHARACTERISTIC FOR ENTITY. Again, as in the other domains, multiple motivations are allowed and can all be fitted into our model. This fact thus underpins our model's reliability as the motivating background behind metonymy.

\section{Contiguity in assemblies and collections}

The metonymical patterns from our initial set that we have not yet covered are CHARACTERISTIC \& ENTITY, INDIVIDUAL \& COLLECTION, OBJECT \& QUANTITY, CENTRAL FACTOR \& INSTITUTION, and HYPONYM \& HYPERONYM. Whereas all previous metonymical patterns could be related fairly straightforwardly to a spatial or temporal basis, the analysis of the remaining patterns requires a further step: we will argue that these patterns can be seen as the extension of the part-whole relationship to the domain of assemblies and collections.

As a first step, let us note that both Cruse (1986) and Seto (1999) distinguish between two types of part-whole relations: taxonomy and partonomy (or meronymy):

[T]axonomy is a 'kind-of' relation while partonomy is a 'part-of' relation. In other words, taxonomy is the relation between a more comprehensive category and a less comprehensive one, while partonomy is the relation between an entity and its parts, such as the relation between a table and its legs (Seto 1999: 93).

This distinction is illustrated by Figure 9. Fir is a kind of tree, whereas arm is a part of the body. "Partonomy is based on real-world constitutive relations; taxonomy is concerned with mental (re)classifications of
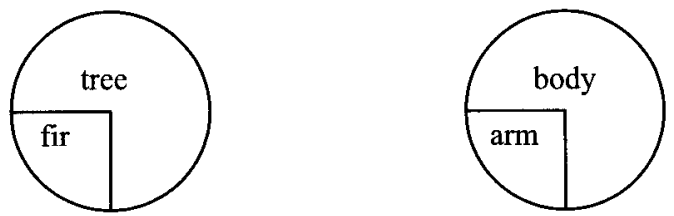

Figure 9. Taxonomy vs. partonymy (Seto 1999: 93). 
categories" (Seto 1999: 94). Hands are thus inextricable parts of the body, whereas firs show no such relation to trees. In the real world, firs are not contiguous to trees. It is our biological classification that forces a (conceptual) contiguity upon them.

We will come back to this specific feature of taxonomical relations in the final part of this section. At this point, we need to point out that the partonomical type of part-whole relations can be broken down into two further types, which we will call assembly and collection. In the figure above, body is an assembly, because it is constituted by widely different parts-hands, legs, ears, eyes, etc. A swarm of bees, in contrast, is a collection, because all its parts are largely identical: a swarm of bees is made up of only bees. Prototypically, assemblies are functional structures of different parts, whereas collections are sets of roughly equal members. There are likely to be borderline cases, in the sense, for instance, in which a committee is a collection of members but the president of the committee has a different function than the ordinary member. Even so, the distinction between prototypical assemblies and prototypical collections is clear enough to be used as an analytical tool. This results in the tripartite structure graphically represented by Figure 10 .

Now, while the part-whole relations that we considered so far involved assemblies that were firmly grounded in the spatial or temporal domain, or a combination of both, we now come across assemblies that are neither predominantly spatial nor predominantly temporal, but that do involve structured entities with different functional parts.

First, consider the CENTRAL FACTOR \& INSTITUTION metonymy, which we took from Norrick (1981). It includes examples such as the press, where the printing machine stands for the institution of which it is a part. The machine is a concrete thing, but the institution has a rather mixed status, involving people and activities next to concrete entities like buildings and newspapers, and printing machines. The mixed nature of the functional whole that we call the press precludes a straightforward analysis as SPATIAL PART \& WHOLE, but an "assembly" interpretation, in
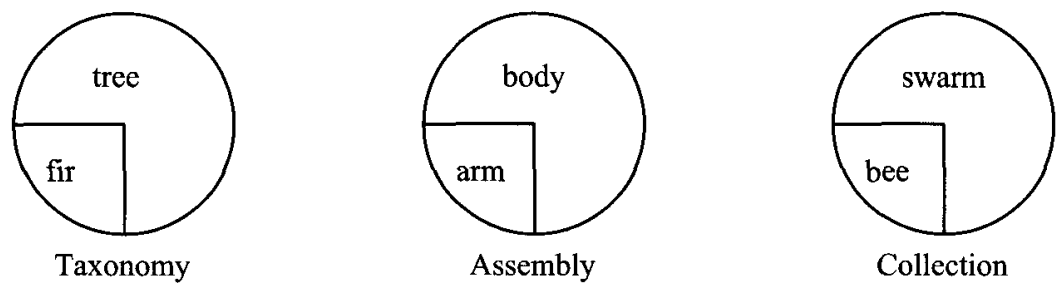

Figure 10. A threefold classification of part-whole relations. 


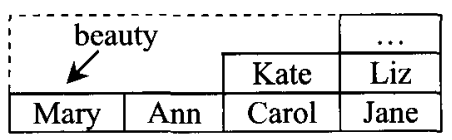

Figure 11. CHARACTERISTIC FOR ENTITY in the case of beauty.

the more general sense of "assembly", is able to deal with this problem. The entity which is conceptualized as an assembly is not necessarily spatial, and may thus also include people, machines, buildings, etc., one of which may be chosen to metonymically stand for the abstract whole to which it belongs.

Second, the CHARACTERISTIC \& ENTITY type of metonymy presents a further extension of the "assembly" interpretation. It differs from the previous one, as it relies on the type of contiguity that we called individuation, i.e. it involves unbounded entities. When a pretty girl is referred to as a beauty, a king as (your) majesty, a judge as (your) honour etc., the people in question are conceptualized as assemblies of characteristics (of which one typical example is selected as the basis for identifying the individual), but these characteristics (beauty, majesty, honour) are essentially unbounded. The individual people, conversely, can be seen as bounded individuations of the unbounded category, as Figure 11 shows.

Some more examples are:

CHARACTERISTIC FOR ENTITY:

Jugend "youth" (Paul 1970: 99); Menge "mass" (Paul 1970: 99); Verwandtschaft "kinship" for "relatives" (Paul 1970: 99); Neuigkeit "novelty" for "bit of news" (Paul 1970: 99); beauté "beauty" (Nyrop 1913: 224); génie "genius" (Nyrop 1913: 224); curiosité "curiosity" (Nyrop 1913: 224); délicatesses "delicacies" (Nyrop 1913: 225); Hang "inclination" for "slope" (Waag 1901: 104); Sänfte "comfort" for "sedan chair" (Waag 1901: 105)

OBJECT \& QUANTITY, our metonymical pattern (19), can be analyzed in a similar way. For instance, in Esnault's (1925) example, un quart "a quarter" metonymically means "a tin of sardines in oil", which always contains this quantity of fish. According to our analysis, QUANTITY can be conceptualized as an unbounded entity. One entity with this quantity can then be metonymically focused upon, just like people with a specific characteristic were. In other words, the admittedly somewhat uncommon OBJECT \& QUANTITY pattern can be analyzed as a subtype of CHARACTERISTIC FOR ENTITY.

Other extensions of CHARACTERISTIC FOR ENTITY may be envisaged when we consider entities that are themselves unbounded. The relationship 
between faith "trust, confidence" and faith "religious belief" is one between two unbounded entities: as trust in God is a characteristic part of the abstract assembly "religious belief", the CHARACTERISTIC FOR ENTITY metonymy applies. Such a relationship in the domain of abstractions like trust and belief parallels the part-whole relationship between unbounded spatial entities that we discussed in connection with Figure 4.

We see, in other words, that part-whole relationships apply to assemblies with different degrees of abstraction, beyond the purely spatial and temporal domains. But what about collections? When we think of functional entities, the shift from assemblies to collections parallels the shift from part-whole relations to contact and adjacency: the entities in collections are typically conceived of as relatively independent but still loosely associated, rather than being connected by strong hierarchical relations, as in typical assemblies. Further, we will have to take into account the distinction between bounded and unbounded cases. Countable collections are bounded wholes, whereas uncountable categories are unbounded. INDIVIDUAL \& COLLECTION, metonymical pattern (18), can thus be classified as either strict contiguity or as individuation, depending on the nature of the collection involved - whether it is countable or not.

Let us start with countable collections. On the one hand, an individual can stand for a collection, as Waag (1901: 92) shows:

Eine Entwicklung zum Kollektivbegriff gleicher Einzelgegenstände (...) zeigt sich bei Rute, das zunächst die lebendige, gewöhnlicher eine abgeschnittene Gerte bezeichnet, hauptsächlich als Züchtigungswerkzeug, am häufigsten jedoch (...) eine Mehrheit von dünnen Zweigen, die zusammengebunden sind.

[A development towards reference to a collection of similar entities ... is shown by Rute, which first refers to the living, or more commonly cut twig, mostly as a punishing instrument, most often still ... as a collection of thin twigs tied together.] (Waag 1901: 92)

On the other hand, a collective term can be used for one entity only, as in German Imme, which in Middle High German times meant "swarm of bees", but now just "bee" (example from Waag 1901). Figure 12 visualizes this example.

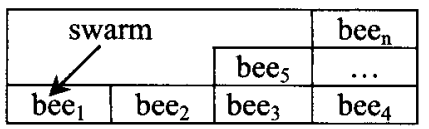

Figure 12. COUNTABLE COLLECTION FOR INDIVIDUAL in the case of Imme. 
A similar phenomenon is attested in the case of uncountable collections. These are unbounded entities made up of single entities: cattle, for instance, is an unbounded whole, constituted by individual entities such as cows, bulls, etc. When one of these entities is picked out and refers to the uncountable collection, or vice versa, a metonymy is created. This is for instance the case with German Frauenzimmer, "woman", and Bursche, "fellow", two examples (taken from Waag 1901) 12 that we will look at in a bit more detail.

First, the German word Frauenzimmer has passed through a whole chain of metonymic changes, including, among others, LOCATION FOR LOCATED. In this paragraph it is the last shift, from "female sex" to "woman", that is of interest, since it shows how the name for an uncountable collection can come to refer to one individual only:

Frauenzimmer ist ursprünglich "Zimmer, in welchem sich die Hausfrau mit dem weiblichen Teil der Hausgenossenschaft aufhält", (...) und bedeutet erst späterhin "Gesamtheit der darin befindlichen Personen", weiterhin "Gesamtheit des weiblichen Geschlechts" (...); im 18. Jahrhundert wird es dann auch für eine einzelne Person üblich

[Frauenzimmer originally means 'room for the lady of the house and the women in the household', ... and only later means 'whole collection of people there', further 'entirety of the female sex' ...; from the 18 th century it commonly refers to a single person.] (Waag 1901: 97).

This last development is represented by Figure 13.

Second, Bursche shows a similar development: originally, it means

... einerseits ein Haus, das von einer aus gemeinschaftlicher Kasse lebenden Gesellschaft bewohnt wurde (...), andrerseits eine solche Gesellschaft selbst namentlich von Studenten, Handwerksgesellen oder Soldaten, bis es schliesslich wegen der Kollektivbedeutung in seiner Form die Bursch(e) im 17. Jahrhundert als Plural aufgefasst und mit einem den einzelnen Teilnehmer bezeichnenden männlichen Singular der Bursch(e) ausgestattet wurde

[on the one hand a house, occupied by a company living from shared funds, on the other hand such a company itself, particularly of students, journeymen or soldiers, until it was, because of its collective meaning in its form die Bursch(e),

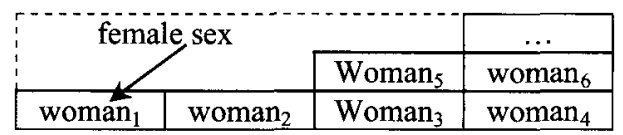

Figure 13. UNCOUNTABLE COLLECTION FOR INDIVIDUAL in the case of Frauenzimmer. 

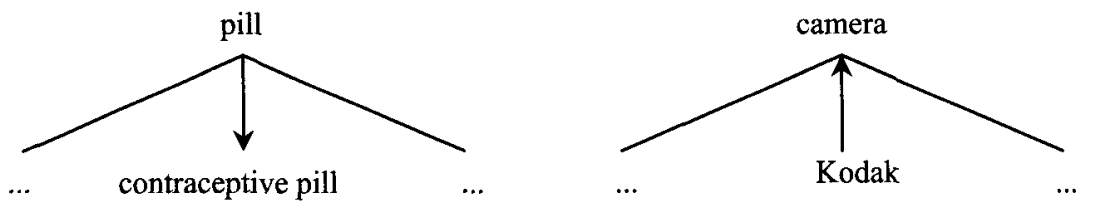

Figure 14. HYPERNYM FOR HYPONYM and HYPONYM FOR HYPERNYM.

interpreted as a plural in the $17^{\text {th }}$ century, and was supplemented with a male singular der Bursch(e), referring to a single participant.] (Waag 1901: 97).

Again the original metonymical change, which we have termed LOCATION FOR LOCATED, is followed by UNCOUNTABLE COLLECTION FOR INDIVIDUAL: a word that originally referred to a company of people now picks out only one individual in this group.

Now that we have established that part-whole relations apply to collections as well as assemblies, we can move on to the third type of relationship that we distinguished in Figure 10, viz. taxonomies. Lexical changes in taxonomies may involve the substitution of a hyponym by a hyperonym, or the substitution of a hyperonym by a hyponym. The former process can be illustrated by English the pill, the latter by Dutch een Kodak. The English word pill does not only refer to all kinds of medical tablets, but also to one specific instance, viz. the contraceptive pill. The hyperonym here refers to one of its hyponyms, often as a sort of euphemism. Conversely, the Dutch word Kodak refers to one type of camera, viz. those of the make Kodak, but it is also often used as a synonym for camera, its hyperonym. Figure 14 illustrates these processes.

Different interpretations of these patterns are possible. The traditional interpretation (which has been in vogue at least since Paul 1880) does not consider them to be cases of metonymy at all, but assumes a distinct type of semantic change: specialization for 'the pill' and generalization for 'Kodak'. A metonymical interpretation is not excluded, however, and it may itself take two different forms, according to whether the categories involved are envisaged from an extensional or an intensional perspective.

Let us first look at the matter from an extensional perspective, since this is probably the most straightforward approach, and take a sentence such as $A$ Kodak is a camera as our starting point. An extensional characterization of the category camera now implies enumerating all possible types of camera-Kodaks, Nikons, Minoltas, Canons, etc. Camera is defined as a (strict) collection of more specific instances, of which Kodak is only one example. Camera is thus seen as a countable collection, from 


\begin{tabular}{|c|c|c|c|}
\hline \multicolumn{2}{|c|}{ camera } & Olympus \\
\cline { 3 - 4 } \multicolumn{2}{|c|}{} & Canon & $\ldots$ \\
\hline Kodak & Minolta & Nikon & Pentax \\
\hline
\end{tabular}

Figure 15. INDIVIDUAL FOR COUNTABLE COLLECTION in the case of Kodak.

\begin{tabular}{|c|c|c|c|}
\hline \multirow{2}{*}{\multicolumn{2}{|c|}{ camera }} & & Olympus \\
\hline & & Canon & $\ldots$ \\
\hline Kodak & Minolta & Nikon & Pentax \\
\hline
\end{tabular}

Figure 16. ENTITY FOR CHARACTERISTIC in the case of Kodak.

which Kodak is merely one individual. Hence, the metonymy Kodak for 'camera' can be interpreted as INDIVIDUAL FOR COUNTABLE COLLECTION, as Figure 15 shows.

Let us now take the same sentence, $A$ Kodak is a camera, but consider it from an intensional perspective. This implies that a category is not defined by means of the types of entities to which it refers, but by the (intensional) characteristics by which it is identified. A camera can then be defined as "a piece of equipment that is used for taking photographs, making films, or producing television pictures" (Collins Cobuild 1995: 230), and a Kodak is "a camera of the make Kodak". Camera is thus a part of the intensional definition of Kodak, and can consequently be metonymically focused upon thanks to the metonymical pattern ENTITY FOR CHARACTERISTIC. This process is shown in Figure 16.

In short, the first interpretation involves "strict" part-whole contiguity, in which the bounded entity Kodak is conceptualized as a part of the bounded collection of cameras. The second interpretation entails individuation, in which camera is seen as an unbounded characteristic of the assembly Kodak.

The same two interpretations can be appealed to for the explanation of HYPERONYM FOR HYPONYM. Extensionally, the contraceptive pill can be seen as a part of the collection of pills, and the metonymy is then classified as COUNTABLE COLLECTION FOR INDIVIDUAL. Intensionally, pill can be conceptualized as one of the characteristics of the contraceptive pill, which entails a classification as CHARACTERISTIC FOR ENTITY. ${ }^{13}$

It is beyond the scope of the present article to decide whether the traditional interpretation of the HYPERONYM FOR HYPONYM and the HYPONYM FOR HYPERONYM patterns in terms of specialization and generalization are more appropriate than the metonymic interpretation. We should recognize, though, that categorial relations of the taxonomical kind are 


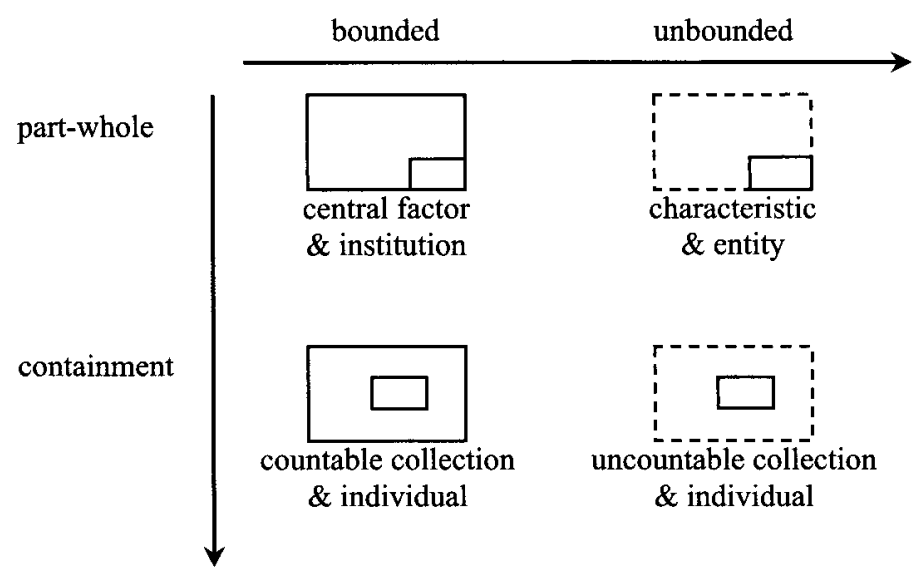

Figure 17. Metonymical patterns in assemblies and collections.

metonymical only in a more or less derived sense. It is only, for instance, when we see categories as sets of members that we can apply the INDIVIDUAL \& COLLECTION metonymy. As we mentioned before, firs and trees are not directly contiguous, but it is only when the abstract category "tree" is conceived of as a collection that the metonymical pattern can apply. However, seeing categories as collections is a specific form of metalinguistic activity that need not be spontaneously or universally present in the average language user. In this respect, we should be careful not to range the HYPERONYM \& HYPONYM pattern too rapidly with metonymy. In any event, we seem to have reached the borderline of metonymy with the HYPERONYM \& HYPONYM pattern: to the extent that it is a metonymy at all, it is a highly specific and peripheral case.

The domain of assemblies and collections is now summarized in Figure 17. Its prototypical core is constituted by contiguity between an assembly and its elements. This type of contiguity mirrors the part-whole relationships from the previous domains, and motivates the metonymical pattern CENTRAL FACTOR \& INSTITUTION. If we then move along the axis of boundedness, we arrive at CHARACTERISTIC \& ENTITY, which allows us to name a characteristic to refer to a bounded or unbounded entity and vice versa. A looser strength of contact, finally, brings us to metonymies involving collections. Here, two patterns can be identified, COUNTABLE COLLECTION \& INDIVIDUAL and UNCOUNTABLE COLLECTION \& INDIVIDUAL, depending on whether the collection is bounded or unbounded, respectively. Hence, it becomes clear that the domain of assemblies and collections displays the same structure as the other domains we discussed above. 


\section{Conclusions}

The point of departure of our exercise in semantic analysis was the recognition that a unitary definition of metonymy in terms of a semantic shift within a domain or a domain matrix is far from unproblematic, given the relative vagueness of the concepts "domain" and "domain matrix". Rather than attempting to refine these concepts, we have explored the possibility of a non-unitary definition of metonymy in the form of a prototypically structured analysis of the notion of contiguity - the concept that used to be seen as the defining feature of metonymy par excellence before Cognitive Linguistics introduced a definition in terms of domains and domain matrices.

Taking spatial part-whole relations as the core of the category, we showed that the set of metonymical patterns that we derived predominantly from the rich pre-structuralist literature on semantic change, can be related to this presumed core case along three interacting dimensions. First, while the strongest form of contiguity involves the partonomic incorporation of one entity in the global structure constituted by the other, weaker forms of contiguity are situated along a dimension leading from part-whole relations over containment and contact to adjacency without contact. Second, while the core case of the contiguity cluster is situated in the spatial and material domain, similar part-whole relations and their derivatives are also found in other domains: in the domain of temporal expressions, in the spatio-temporal domain of actions, events, and processes, and in the domain of functional assemblies and collections. Third, while the central part-whole configuration links concrete and bounded parts and wholes, extended patterns involve unbounded (and possibly abstract) entities. These three interacting dimensions are shown in Figure 18.

The prototype-theoretical nature of the resulting network of extensions resides not just in the choice of a core reading as a starting-point for the analysis, but also in the structural characteristics of the network: in the way in which the features of the central case are systematically transformed, extrapolated, weakened in the derived cases; in the way in which the various lines of extension interact to form a multidimensional structure; and in the way in which individual extensions may be multiply motivated. All of these features have been noted before as typical of prototypicality; see e.g. Geeraerts (1997).

Crucially, none of the lines that connect the extensions to the core themselves involve a metonymical change (which would condemn the whole enterprise to a certain degree of circularity). The mechanisms of extension, in fact, are largely based on similarity: metaphorical similarity in 


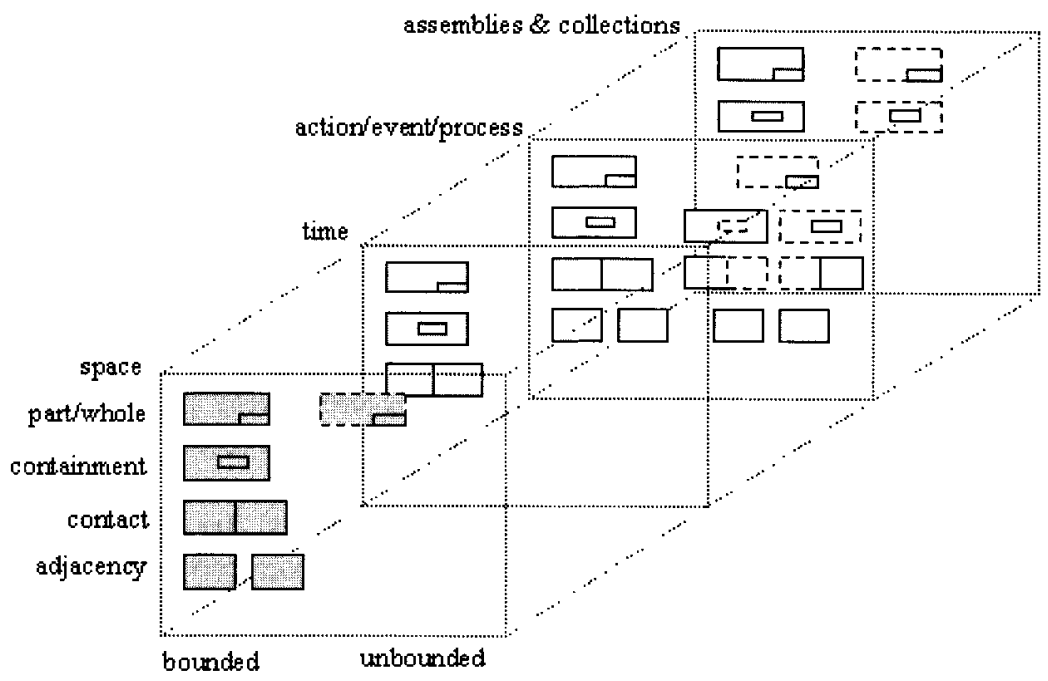

Figure 18. The prototypical category of metonymical patterns.

the form of a shift from the spatial and material domain to temporally characterized entities and to functional and abstract wholes, and similarity in the form of a gradual weakening of the contiguous part-whole relationship to looser forms of contact and adjacency.

The success of the analytical attempt to bring together different types of metonymy into a prototypically structured category establishes the basic point we set out to explore: a definition of metonymy in terms of contiguity is possible, if we accept a non-unitary, prototype-based analysis of contiguity. This does not mean, to be sure, that all questions have been answered. First, it is clear that not all contiguous entities can metonymically refer to one another. Metonymies, and their directionality, are also motivated by pragmatic factors, which we left largely unexplored. Second, as we have already mentioned, metonymy interacts with certain grammatical phenomena. These processes, which we largely ignored, certainly deserve further treatment. Third, it will be necessary to enlarge the empirical basis of the approach by incorporating even more metonymical patterns and examples. This should include the consultation of other linguistic sources and a supplementation of the present metonymical patterns (most of which are lexical) with more predicational, propositional and illocutionary metonymies. On the basis of what was achieved in the previous pages, however, we are confident that such an extended analysis will not radically alter the basic picture that we have drawn, even though we may expect multiple refinements on individual points. 
The attempts of Cognitive Linguistics to bring a specific perspective to the study of metonymy have so far been dominated by a focus on domains and domain matrices. The present analysis shows that there is another typically Cognitive Linguistic concept that may be brought to bear on the definition of metonymy, viz. that of prototypicality. It is not yet clear which perspective, the domain-related one or the prototype-related one, will ultimately prove to be most fruitful, but at least it has become clear that the study of metonymy within Cognitive Linguistics should take both perspectives into account. Depending on how one evaluates the domain matrix definition of metonymy, our prototype-based analysis may either replace this definition (if it turns out to be insufficient for independent reasons) or provide a network-like expansion of the schematic domain matrix account.

Received 10 January 2005

University of Leuven, Belgium

Accepted 15 March 2005

\section{Notes}

* Authors' affiliation: University of Leuven, Research Group Quantitative Lexicology and Variational Linguistics, Blijde-Inkomststraat 21, 3000 Leuven, Belgium. Authors' e-mail addresses:〈yves.peirsman@arts.kuleuven.be〉,〈dirk.geeraerts@arts.kuleuven.be〉.

1. We will symbolize a metonymical pattern by ENTITY $1 \&$ ENTITY 2 when the direction of the meaning shift is irrelevant. In order to refer to a specific direction, we will use the notation SOURCE FOR TARGET. In other words, ENTITY 1 \& ENTITY 2 generalizes over ENTITY 1 FOR ENTITY 2 and ENTITY 2 FOR ENTITY 1.

2. This inventory is not a simple enumeration of all the metonymical patterns that are found in these five studies of metonymy. Instead, two major adaptations were made. First, very idiosyncratic patterns were, if possible, subsumed under more general patterns from other sources. Paul's (1880) sOUND FOR ANIMAL, for instance, is a clear example of PRODUCER \& PRODUCT, and Nyrop's (1913) COLOUR FOR CLOTH seems a more specific application of CHARACTERISTIC \& ENTITY. When there is considerable disagreement between our sources as to where the pattern belongs, we listed it separately. This was the case with, for instance, PIECE OF CLOTHING \& PERSON, which was treated as SPATIAL PART \& WHOLE by Paul, Nyrop and Waag, as CONTAINER \& CONTAINED by Norrick, and as PERSON \& FASHION by Esnault. Second, overlap between the various sources was removed. The pattern LOCATION \& LOCATED, for instance, was not literally named by any of our sources, but combines the frequently mentioned PLACE \& PEOPLE with Nyrop's THING FOR PLACE and Norrick's LOCALITY \& OCCUPANT. Adaptations such as these were necessary to present a convenient inventory of metonymical patterns that best suits our purposes.

3. The symbols following the patterns indicate the sources that they were named by, where $\mathbf{P}=$ Paul (1880), W = Waag (1901), $\mathrm{Ny}=$ Nyrop (1913), $\mathrm{E}=$ Esnault (1925) and No $=$ Norrick (1981).

4. It has to be noted that, traditionally, PART \& WHOLE metonymies have often been classified as synecdoche (cf. Fontanier 1968). In contemporary linguistics, however, the dis- 
tinction between metonymy and synecdoche is often blurred, because of its problematic nature. Yet, some researchers, such as Seto (1999), still defend a specific treatment of synecdoche.

5. This paper presents a rational reconstruction of the relationships between the metonymical patterns in the inventory. It thus addresses the developments in the use of the term metonymy in the linguistic literature rather than the historical developments of the metonymical patterns themselves.

6. Note that we use the term "domain" in a slightly different context than the one above. Here, it refers to the four conceptual realms in which contiguity can occur (space, time, action/event/process and category), and not to "a semantic structure that functions as the base for at least one concept profile (typically, many profiles)" (Croft 2002: 166).

7. In the literature, another analysis of these examples can be found. Kövecses (2002), in particular, classifies a metonymy such as Mary speaks Spanish as SUBEVENT FOR COMPLEX EVENT. The reason for this classification is intuitively clear: Mary does not only speak the language, but also writes it, listens to it, etc., so that the act of speaking can be conceptualized as a smaller part of a complex action. The way in which this metonymy is classified will thus depend on the conceptualization that is chosen. Either we perceive of the knowledge of a language as an unbounded state in time and we classify the metonymy as ACTION FOR STATE, or we see the knowledge of a language as a complex set of related events and classify the metonymy as SUBEVENT FOR COMPLEX EVENT.

8. The importance of a functional rather than a spatial conception of containment has been pointed at early in the history of Cognitive Semantics; see Vandeloise (1986).

9. It has to be noted that this metonymical pattern often overlaps with another pattern that is generally called ACTION \& RESULT. In many of the examples above, the patient is at the same time the result of the action. In general, ACTION \& RESULT metonymies can often be subsumed under other metonymical patterns. When the result is also the patient of the action, a classification as ACTION \& PATIENT seems appropriate. When the result, in contrast, is a state caused by the action, it seems logical to subsume the metonymy under CAUSE \& EFFECT. ACTION \& RESULT metonymies thus seem to form a subtype of other metonymical patterns, rather than to constitute their own separate type.

10. In the literature (see e.g. Kövecses and Radden 1998; Brdar and Brdar-Szabó 2003), another action metonymy is distinguished, viz. MANNER FOR ACTION. There is, however, no reason to claim the existence of a new metonymical pattern to accommodate these cases. In general, the metonymies that are distinguished as MANNER FOR ACTION fall into two groups. The first group is represented by Kövecses and Radden's (1999) example She tiptoed to her bed. Setting aside the morphological issue we referred to earlier, we believe that metonymies such as this one should be subsumed under INSTRUMENT FOR ACTION, because the tips of the toes are the instruments of the action performed. The second group of MANNER FOR ACTION metonymies is represented by Brdar and BrdarSzabó's (2003) I must be open with her for I must speak openly with her and by Lapata and Lascarides's (2003) easy problem. This group can be analyzed as CHARACTERISTIC FOR ENTITY, since an action can be seen metaphorically as an entity that has "manner" as one of its characteristics. Note, finally, that Langacker (1999) calls this last example an "active-zone metonymy", since it activates an implicit relation with respect to which the problem is easy.

11. Note that we use the terms agent and patient rather broadly: they can also refer to the participants in a stative relation such as possession. 
12. Waag (1901) did not distinguish between this metonymical pattern and the previous one, so that they are both represented by the same metonymical pattern in our inventory.

13. In metonymical patterns such as HYPERONYM \& HYPONYM, prototypicality plays a major role. Prototypicality is the prime motivation behind the choice of the source in HYPONYM FOR HYPERONYM metonymies and behind the interpretation of HYPERONYM FOR HYPONYM metonymies. In the former pattern, it is the most prototypical hyponym which is chosen as the source of the metonymy. This is the reason why Kodak and not Olympus or Pentax can refer to cameras in general. In the latter pattern, it is prototypicality which guides the calculation of the metonymical goal. The metonymical interpretation of pill as "contraceptive pill"--and not as pills against headache, stomachache, etc. - can be accounted for by the prototypical status of the former. In fact, the influence of prototypicality in instances such as these may be so significant that it suggests yet another way of looking at the HYPONYM FOR HYPERONYM cases: the shift may be due to similarity with the prototype, in the sense that Nikons and Minoltas and so on are equated with the Kodak prototype.

\section{References}

Barcelona, A.

2002 Clarifying and applying the notions of metaphor and metonymy within Cognitive Linguistics: an update. In Dirven, R. and R. Pörings (eds.), Metaphor and Metonymy in Comparison and Contrast. (Cognitive Linguistics Research 20.) Berlin/New York: Mouton de Gruyter, 207-278.

2003 Metonymy in cognitive linguistics. An analysis and a few modest proposals. In Cuyckens, H., Th. Berg, R. Dirven and K.-U. Panther (eds.), Motivation in Language, Studies in Honor of Günter Radden. Amsterdam/Philadelphia: John Benjamins, 223-255.

Blank, A.

1999 Co-presence and succession: A cognitive typology of metonymy. In Panther, K.-U. and G. Radden (eds.), Metonymy in Language and Thought. Amsterdam and Philadelphia: John Benjamins, 169-191.

Bonhomme, $\mathrm{M}$.

1987 Linguistique de la métonymie. Bern: Peter Lang.

Brdar, M. and R. Brdar-Szabó

2004 Metonymic coding of linguistic action in English, Croatian and Hungarian. In Panther, K.-U. and L. Thornburg (eds.), Metonymy and Pragmatic Infer-

Croft, W.

2002 The role of domains in the interpretation of metaphors and metonymies. In Dirven, R. and R. Pörings (eds.), Metaphor and Metonymy in Comparison and Contrast. (Cognitive Linguistics Research 20.) Berlin/New York: Mouton de Gruyter, 161-205.

Croft, W. and D. A. Cruse

2005 Cognitive Linguistics. Cambridge: Cambridge University Press.

Cruse, D. A.

1986 Lexical Semantics. Cambridge: Cambridge University Press.

Dirven, $\mathbf{R}$.

2002 Metonymy and metaphor: Different mental strategies of conceptualisation.

In Dirven, R. and R. Pörings (eds.), Metaphor and Metonymy in Comparison 
Eco, U. 1973

Esnault, G.

1925 Métaphores occidentales. Essai sur les valeurs imaginatives concrètes $d u$ Français parlé en Basse-Bretagne comparé avec les patois, parlers techniques

Feyaerts, $\mathbf{K}$.

and Contrast. (Cognitive Linguistics Research 20.) Berlin/New York: Mouton de Gruyter, 75-111.

1999 Metonymic hierarchies. The conceptualization of stupidity in German idiomatic expressions. In Panther, K.-U. and G. Radden (eds.), Metonymy in Language and Thought. Amsterdam and Philadelphia: John Benjamins, 309 -332.

2000 Refining the inheritance hypothesis: interaction between metaphoric and metonymic hierarchies. In Barcelona, A. (ed.), Metaphor and Metonymy at the Crossroads: A Cognitive Perspective. Berlin/New York: Mouton de Gruyter, 59-78.

Fontanier, P.

1968 Les figures du discours. Paris: Flammarion.

Frisson, S. and M. J. Pickering

1999 The processing of metonymy: Evidence from eye movements. Journal of Experimental Psychology: Learning, Memory and Cognition 25, 13661383.

Geeraerts, D.

1988 Cognitive grammar and the history of lexical semantics. In Rudzka-Ostyn,

B. (ed.), Topics in Cognitive Linguistics. Amsterdam/Philadelphia: John Benjamins, 647-677.

1997 Diachronic Prototype Semantics. Oxford: The Clarendon Press.

Goossens, L.

1995 Metaphtonymy: the interaction of metaphor and metonymy in expressions for linguistic action. In Goossens, L. et al. (eds.), By Word of Mouth: Metaphor, Metonymy and Linguistic Action in a Cognitive Perspective. Amsterdam/Philadelphia: John Benjamins, 159-174.

Jakobson, R. 2002

The metaphoric and metonymic poles. In Dirven, R. and R. Pörings (eds.), Metaphor and Metonymy in Comparison and Contrast. (Cognitive Linguistics Research 20.) Berlin/New York: Mouton de Gruyter, 41-47.

Johnson, M. 1987

The Body in the Mind: The Bodily Basis of Reason and Imagination. Chicago: The University of Chicago Press.

Kövecses, Z.

2002 Metaphor: A Practical Introduction. Oxford: Oxford University Press.

Kövecses, Z. and G. Radden

1998 Metonymy: Developing a cognitive linguistic view. Cognitive Linguistics 9 , $37-77$.

Kronasser, $\mathrm{H}$.

1952 Handbuch der Semasiologie. Heidelberg: Carl Winter.

Lakoff, $\mathrm{G}$.

1987 Women, Fire and Dangerous Things. What Categories Reveal about the Mind. Chicago/London; The University of Chicago Press. 
Lakoff, G. and M. Johnson

1980 Metaphors We Live By. Chicago/London: The University of Chicago Press.

Langacker, R. W.

1999 Grammar and Conceptualization. Berlin/New York: Mouton de Gruyter.

Lapata, M. and A. Lascarides

2003 A probabilistic account of logical metonymy. Computational Linguistics 29 (2), 261-315.

Norrick, N. R.

1981 Semiotic Principles in Semantic Theory. Amsterdam Studies in the Theory and History of Linguistic Science IV. (Current Issues in Linguistic Theory 20.) Amsterdam/Philadelphia: John Benjamins.

Nunbert, G. D.

1978 The Pragmatics of Reference. Bloomington: The Indiana University Linguistics Club.

Nyrop, K.

1913 Grammaire historique de la langue française. Tome $I V$. Copenhagen: Gyldendalske Boghandel, Nordisk Forlag.

Panther, K.-U. and L. Thornburg

1999 The potentiality for actuality metonymy in English and Hungarian. In Panther, K.-U. and G. Radden (eds.), Metonymy in Language and Thought. Amsterdam/Philadelphia: John Benjamins, 333-357.

in press Metonymy. In Geeraerts, D. and H. Cuyckens (eds.), Handbook of Cognitive Linguistics. Oxford/New York: Oxford University Press.

Paul, H.

1970 Prinzipien der Sprachgeschichte. Tübingen: Max Niemeyer Verlag.

Riemer, N.

2001 Remetonymizing metaphor: Hypercategories in semantic extension. Cognitive Linguistics 12, 379-401.

Ruiz de Mendoza, F. and J. Otal Campo

2002 Metonymy, Grammar and Communication. Granada: Editorial Comares.

Schmid, H.-J.

1993 Cottage und Co., idea, start vs. begin: die Kategorisierung als Grundprinzip einer differenzierten Bedeutungsbeschreibung. Tübingen: Niemeyer.

Schofer, P. and D. Rice

1977 Metaphor, metonymy and synecdoche revis(it)ed. Semiotica 21, 121-149.

Seto, $\mathrm{K}$.

1999 Distinguishing metonymy from synecdoche. In Panther, K.-U. and G. Radden (eds.), Metonymy in Language and Thought. Amsterdam/Philadelphia: John Benjamins, 91-120.

Sinclair, J. et al.

1995 Collins Cobuild English Dictionary. London: HarperCollins Publishers.

Taylor, J. R.

2002 Cognitive Grammar. Oxford/New York: Oxford University Press.

Tversky, B. and K. Hemenway

1984 Objects, parts, and categories. Journal of Experimental Psychology 113, 169-193.

Ullmann, $S$.

1967 The Principles of Semantics. (Glasgow University Publications 84.) Oxford:

Blackwell. 


\section{$316 Y$ Y. Peirsman and D. Geeraerts}

Vandeloise, C. 1986

L'espace en français. Paris: Seuil.

Waag, A. 1901

Bedeutungsentwicklung unseres Wortschatzes. Lahr i. B.: Moritz Schauenburg. 